István P. BEJCZY

\title{
LES VERTUS CARDINALES \\ DANS L'HAGIOGRAPHIE LATINE DU MOYEN ÂGE ${ }^{*}$
}

\section{Introduction}

Les quatre vertus cardinales (prudentia, iustitia, fortitudo, temperantia), concepts issus de la philosophie de l'Antiquité, ont connu un succès extraordinaire dans l'histoire de l'Église latine. Initialement formulées par Platon puis reprises par Aristote dans son Éthique à Nicomaque, les quatre vertus occupaient une place centrale dans le stoïcisme grec et romain. Malgré ces origines païennes, les vertus furent non seulement intégrées dans le christianisme dès l'ère patristique, mais aussi érigées en critère de sainteté aux Temps Modernes. Le schéma des trois vertus théologales (fides, spes, caritas) et des quatre vertus cardinales apparut pour la première fois dans le procès de canonisation de Bonaventure en $1482^{1}$; aux siècles suivants, l'utilisation de ce schème devint la règle, grâce surtout aux décrets du pape Urbain VIII (r. 1623-1644) qui exigeait des preuves de la vertu des saints. La règle reçut sa formalisation définitive en 1734/ 1738, lorsque Prosper Lambertini, pape depuis 1740 sous le nom de Benoît $\mathrm{XIV}$, publia son ouvrage sur les béatifications et les canonisations. Les quatre vertus et leurs sous-espèces y font l'objet d'un long chapitre suivant la trame de la Summa theologiae de Thomas d'Aquin ${ }^{2}$. Entre 1917 et 1983, le Codex iuris canonici prescrivait l'examen formel des vertus théologales ainsi que cardinales des confessores parmi les saints futurs; seuls

* Cet article est issu du projet de recherche «A Genealogy of Morals: The Cardinal Virtues in the Middle Ages», dirigé par l'auteur et subventionné par l'Organisation Néerlandaise de la Recherche Scientifique (N.W.O.) ainsi que par la Radboud Universiteit Nijmegen. Je tiens à remercier Céline Billot-Vilandrau, Bert Roest, Ineke van 't Spijker et François De Vriendt pour leurs aimables conseils.

$\mathrm{Vu}$ le nombre de textes cités, nous avons opté pour un système de renvois codés: le nom du saint, précédé d'un astérisque (*), renvoie à la liste donnée dans l'Appendice (cf. infra, p. 349-360), où le lecteur trouvera la référence précise des extraits mentionnés et de leurs éditions.

${ }^{1}$ L. Hertling, Canonisation, in Dictionnaire de spiritualité, t. 2, Paris, 1937, col. 82. Pour ce qui concerne les procès informatifs diocésains, la primeur semble revenir à Catherine de Sienne (1411/1416); voir ci-dessous p. 340-341.

${ }^{2}$ P. LAMBERTINI (Benoît XIV), De servorum Dei beatificatione et beatorum canonizatione, $2^{\mathrm{e}}$ ed., 4 t., Padoue, 1743. Voir c. 3.24, De virtutibus cardinalibus seu moralibus, prudentia, justitia, fortitudine, temperantia et earum annexis, et de heroicitate uniuscujusque ex ipsis (t. 3, p. 208-233); le chapitre 3.23 (ibid., p. 191-208) discute des vertus théologales.

Analecta Bollandiana, 122 (2004), p. 313-360. 
ceux qui avaient observé ces vertus à un degré héroïque pouvaient prétendre à la canonisation ${ }^{3}$. Le droit canonique actuel ne parle qu'en termes généraux de l'héroïcité des vertus requise pour les saints confesseurs ${ }^{4}$; cependant, les dossiers de canonisation composés de nos jours respectent habituellement le schème traditionnel des sept vertus.

$\mathrm{Si}$ les vertus cardinales ont fait leur entrée dans les canonisations relativement tard, elles figurent dans l'hagiographie latine dès le début du Moyen Âge. C'est ce phénomène, remarquable à divers égards, que nous proposons d'explorer dans cet essai. Nous avons repéré dans les collections principales de sources hagiographiques plus d'une centaine de Vies écrites avant 1500 qui évoquent les vertus cardinales ${ }^{5}$; les pages qui suivent seront consacrées à leur analyse. Vu l'abondance des biographies de saints et leur accès parfois difficile, notre dossier ne saurait prétendre à l'exhaustivité, mais nous croyons cependant que nos données sont représentatives de l'ensemble de l'hagiographie latine du Moyen Âge. Les textes portant sur le Christ et sur Marie méritent une étude spéciale et ne seront donc pas discutés ici; nous comptons aborder cette matière dans une prochaine étude. Nous étudierons successivement les débuts de la tradition (II), son développement jusqu'à la fin du XII siècle (III et IV) et son. évolution dans les derniers siècles du Moyen Âge (V et VI). Pour ce qui concerne le contenu des vertus, la coexistence de significations classiques et chrétiennes nous intéressera particulièrement.

${ }^{3}$ Codex iuris canonici Pii X..., Rome, 1917, can. 2104: In causis confessorum discuti debet dubium: an constet de virtutibus theologalibus Fide, Spe, Caritate tum in Deum tum in proximum, necnon de cardinalibus Prudentia, Iustitia, Temperantia, Fortitudine, earumque adnexis in gradu heroico...

${ }^{4}$ Voir W. Schulz, Das neue Selig- und Heiligsprechungsverfahren, Paderborn, 1988, avec un appendice contenant les conditions et les règles les plus importantes en vigueur aujourd'hui.

${ }^{5}$ Nous avons examiné les textes publiés dans AASS Database, Patrologia Latina Database, CLCLT-5 (2002), Analecta Bollandiana (1882-2002) et B. MOMBRITIUS, Sanctuarium seu vitae sanctorum, $2^{\mathrm{e}}$ ed., 2 t., Paris, 1910, ainsi que les Vies mentionnées dans A. VAUCHEZ, La sainteté en Occident aux derniers siècles du Moyen Age (= Bibliothèque des Écoles françaises d'Athènes et de Rome, 241), Rome, 1981, pour autant que celles-ci nous étaient disponibles (y compris la Legenda aurea de Jacques de Voragine). En outre, nous avons examiné un maximum de Vies de certains saints particuliers lorsque notre argumentation semblait l'exiger; voir infra, n. 19 (Benoît), 84 (Thomas d'Aquin), 85-87 (Catherine de Sienne), 88 (Claire de Montefalco), 90 (François d'Assise), 93 (Bernardin de Sienne), 95 (Bonaventure), 96 (Léopold d'Autriche). 


\section{Les débuts de la tradition chez les Pères latins}

Les premières références aux vertus cardinales dans l'hagiographie latine remontent au $\mathrm{IV}^{\mathrm{e}}$ siècle. La tradition s'amorce avec deux emprunts directs à un texte grec, la Vie d'Antoine, écrit par Athanase en 357. Dans ce récit, Antoine prêche, en discours direct, l'abandon des richesses terrestres; mieux vaut l'accumulation des biens qui nous ouvrent les portes

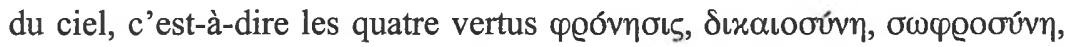
$\dot{\alpha} v \delta \varrho \varepsilon i \alpha$ (les termes sont identiques à ceux qu'utilise Platon) ainsi que plusieurs autres qualités, telles que l'assistance aux pauvres, la stabilité dans la foi et l'hospitalité. Deux traductions latines de la Vie, datant d'avant 370/375 - l'une anonyme et peu répandue, l'autre effectuée par Évagre d'Antioche qui connut une grande popularité au Moyen Âge retiennent les vertus cardinales dans la liste des véritables biens de $1^{\prime}$ homme ${ }^{6}$; de cette dernière traduction, le passage fut repris dans la Vie de Tillon de Solignac $(† 702)$, œuvre de date inconnue. Il importe de noter que les quatre vertus figurent dans ces textes en tant que qualités recommandées par le saint, et non comme ses caractéristiques personnelles, approche que nous rencontrons également dans un nombre limité d'autres sources médiévales; on imagine pourtant aisément que les lecteurs aient associé le saint aux vertus exaltées dans ses paroles.

Seul un autre emprunt des quatre vertus à l'hagiographie grecque nous est parvenu dans les sources latines. La légende de Barlaam et Josaphat, diffusée en de nombreuses versions latines à partir du $\mathrm{XI}^{\mathrm{e}}$ siècle, contient un long exposé du premier (à nouveau en discours direct) visant à la conversion de Josaphat; au cours de cet exposé, Barlaam mentionne brièvement les quatre vertus, principaux ingrédients de la vie morale chrétienne ${ }^{7}$. En outre, deux textes latins associent un saint hellène aux quatre vertus sans précédent direct dans l'hagiographie grecque (*Helena, *Paulus); pour le reste, nos sources latines portent exclusivement sur des saints originaires de l'Occident.

\footnotetext{
${ }^{6}$ Pour le texte grec, voir l'édition de G. J. M. BARTELINK, Athanase d'Alexandrie, Vie d'Antoine (= Sources chrétiennes, 400), Paris, 1994, p. 182. Voici les textes latins: ...<quae possumus nobiscum tollere>, quae sunt pudicitia, prudentia, iustitia, fortitudo, intellectus, dilectio, amor pauperum, fides in Christo, patientia sine ira, hospitalitas? Ista enim possidentes invenimus illa ante nos ibi facientia nobis hospitium in terra mitium (*Antonius [1]; le texte est corrompu au début); illud potius debemus expetere, quod nos ducat ad caelum; sapientiam scilicet, castitatem, justitiam, virtutem, sensum pervigilem, pauperum curam, fidem in Christo robustam, animum irae victorem, hospitalitatem (*Antonius [2], cf. *Tillo).

${ }^{7}$ Pour le texte grec de Jean Damascène, voir $P G$ 96, col. 1037D.
} 
Le premier auteur latin à incorporer les quatre vertus dans l'hagiographie sans dépendre d'exemples grecs fut Ambroise de Milan. Dans son De excessu fratris (378), il fait l'éloge de son frère aîné défunt, Satyre, qui s'était occupé des affaires temporelles dans la maison de son cadet. Le texte contient un long exposé sur sa prudence, son courage, sa tempérance, sa justice et quelques-unes de leurs sous-espèces. L'état laïc de Satyre peut-il avoir stimulé le recours aux quatre vertus que les stoïciens latins, notamment Cicéron, avaient habituellement liées à la vie publique? Dans le cas d'Ambroise, l'hypothèse semble peu probable. Ambroise est l'auteur du De officiis, calqué sur l'ouvrage cicéronien qui porte le même nom; l'évêque de Milan y lance une attaque acerbe contre la conception stoïcienne des vertus cardinales qu'il réclame pour la foi en les redéfinissant selon les devoirs des chrétiens envers Dieu, le prochain et soi-même ${ }^{8}$. Ambroise introduisit ainsi les quatre vertus dans la morale chrétienne, et c'est à lui que l'on doit le terme de «vertus cardinales». C'est encore lui, comme on peut maintenant l'affirmer, qui a établi dans le monde latin la tradition hagiographique des louanges des saints suivant le schéma des quatre vertus.

De fait, la polémique avec le stoïcisme est absente du De excessu fratris; à plusieurs reprises, Ambroise cite, en les approuvant, les définitions des vertus proposées par les anciens «sages» pour les apparenter ensuite à la religion chrétienne ${ }^{9}$. La prudence de Satyre consistait surtout à reconnaître ses obligations d'obéissance, de révérence et de gratitude envers son Créateur ainsi que celle de l'amour du prochain; la vigilance (cautio), élément principal de la prudence dans le stoïcisme, joue un rôle plutôt secondaire. Son courage résidait dans l'affrontement du danger et la persévérance dans le bien, éléments traditionnels de cette vertu mais conçus, dans son cas, comme adaptés aux desseins divins. La chasteté, la parcimonie et surtout la modestie presque excessive caractérisaient la tempérance de Satyre, qualités qui semblent se rapprocher de la triade cicéronienne de continentia, clementia et modestia ${ }^{10}$; on sent pourtant

\footnotetext{
${ }^{8}$ Voir notamment M. BECKER, Die Kardinaltugenden bei Cicero und Ambrosius: De officiis (= Chrêsis, 4), Bâle, 1994, ainsi que l'édition récente de l'œuvre d'Ambroise par M. TESTARD (= Corpus Christianorum. Series Latina, 15), Turnhout, 2000.

${ }^{9}$ Non mediocris igitur prudentiae testimonium, quae ita a sapientibus definitur... Quod etiam mundi sapientes nostris hausere de legibus... (*Satyrus, c. 1.42 [p. 232]); Est ergo prudentis agnoscere se ipsum, et, quemadmodum a sapientibus definitum est, secundum naturam vivere (*Satyrus, c. 1.45 [p. 234]).

${ }^{10}$ Cicéron, De inventione 2.54.164, ed. E. STRÖBEL (= Bibliotheca Scriptorum Graecorum et Romanorum Teubneriana), Leipzig, 1915, p. 149.
} 
qu'Ambroise vise à présenter son frère sous l'angle de l'humilité chrétienne. En fin de compte, son désir d'aider les pauvres domine son sens de la justice, qualité qui n'est outrepassée que par sa clémence. Même si, pour un Cicéron, la bénignité faisait partie de la justice, la conception de cette dernière vertu dans le De excessu fratris semble s'inspirer de l'Évangile: dans le sermon sur la montagne, le Christ range l'assistance aux pauvres parmi les œuvres de la justice; de plus, la modération imposée aux exigences de la justice par la miséricorde est caractéristique du christianisme $^{11}$. Cependant, l'opposition d'Ambroise aux idées reçues de l'éthique stoïcienne reste latente dans cet ouvrage. L'évêque de Milan souscrit même à l'ancienne doctrine de la connexion nécessaire des vertus cardinales $^{12}$, comme Jérôme et Augustin devaient le faire après lui. Jérôme allait à son tour être suivi par deux hagiographes des $\mathrm{VIII}^{\mathrm{e}}$ et XI $\mathrm{XI}^{\mathrm{e}}$ siècles, qui ont ainsi assuré la survie de cette doctrine stoïcienne dans les Vies de saints médiévales ${ }^{13}$.

\section{La diffusion de la tradition durant le haut Moyen Âge}

Pour le besoin de l'argumentation, nous avons divisé notre recueil des sources postérieures à la période patristique en deux sections que nous traiterons séparément. La première section, de loin la plus volumineuse, comprend les textes écrits entre 500 et 1200 environ. Comme il est impossible de discuter chaque texte en détail, nous nous trouvons dans l'obligation de nous limiter à une vue d'ensemble et aux enseignements essentiels de cette enquête.

Tout d'abord, on peut constater que le nombre de sources hagiographiques évoquant les vertus cardinales s'accroît avec le temps de façon assez spectaculaire, même en tenant compte de la datation approximative de certains textes. Si nous n'avons relevé qu'un seul texte pour les $\mathrm{V}^{\mathrm{e}}$ et

\footnotetext{
"Voir S. KUTTNER, A Forgotten Definition of Justice, in Mélanges G. Fransen, ed. S. KUTTNER - A. M. STICKLER, t. 2 (= Studia Gratiana, 20), Rome, 1976, p. 94-95.

12 *Satyrus, c. 1.57 [p. 239].

13 *Eligius [col. 519C]: Praecipuas denique virtutes ... prudentiam scilicet, justitiam, fortitudinem et temperantiam, ita in se connexas, sibique mutuo cohaerentes excoluit, ut pene in singulis emineret; *Bononius: Quattuor principales virtutes scripturarum assertionibus noverat appetendas, prudentiam, iustitiam, fortitudinem, temperantiam, ita sibi invicem nexas et mutuo cohaerentes, ut qui unam non habuerit, omnibus careat. Quas omnes sic habuit vir venerabilis, ut tamen emineret in singulis. Ce dernier passage est repris de Jérôme, Epistula 66.3, ed. I. HILBERG (= Corpus Scriptorum Ecclesiasticorum Latinorum, 54), Vienne, 1910, p. 649 (voir aussi R. GRÉGOIRE, Il libro delle virtù e dei vizi, in Schede medievali, 5 [1983], p. 345-346); *Eligius puise visiblement à la même source.
} 
$\mathrm{VI}^{\mathrm{e}}$ siècles, le VII ${ }^{\mathrm{e}}$ siècle fournit trois exemples, et les $\mathrm{VIII}^{\mathrm{e}}$ et $\mathrm{IX}^{\mathrm{e}}$ siècles en offrent chacun huit ${ }^{14}$. Quinze textes émanent du $\mathrm{X}^{\mathrm{e}}$ siècle $^{15}$, vingt-six du $\mathrm{XI}^{\mathrm{e} 16}$ et vingt-huit du XII ${ }^{\mathrm{e} 17}$. Dans trois autres cas remontant sans doute avant 1200 , la datation reste très incertaine ${ }^{18}$. La liste des vertus apparaît habituellement au début du récit, dans la description du caractère et de la physionomie du saint. Quant au statut social des saints, les évêques ne sont pas plus nombreux dans notre dossier que les cénobites, malgré la connexion traditionnelle des vertus à la vie publique. Les milieux bénédictins prévalent, notamment $\mathrm{du}_{\mathrm{IX}} \mathrm{e}^{\mathrm{e}}$ au XI $\mathrm{XI}^{\mathrm{e}}$ siècles, même si les quatre vertus ne sont pas présentes dans les Vies consacrées à Benoît lui-même ${ }^{19}$.

Selon une des rares études disponibles portant sur les catalogues de vertus dans l'hagiographie médiévale, les quatre vertus cardinales n'apparaîtraient que rarement ensemble dans les Vies écrites entre 500 et 1200;

${ }^{14} \mathrm{~V}^{\mathrm{e}} / \mathrm{VI}^{\mathrm{e}}$ : *Hilarius Arelatensis; vII ${ }^{\mathrm{e}}$ *Furseus, *Gregorius I, *Richarius; VIII ${ }^{\mathrm{e}}$ : *Bertuinus, *Eligius, *Eustadiola, *Guthlacus, *Lupus [1], *Silvinus, *Trudo (il manque le courage), *Ursmarus [1]; $\mathrm{IX}^{\mathrm{e}}$ : *Adalhardus, *Ansegisus, *Audoenus, *Desiderius, *Droctoveus, *Eparchius, *Helena, *Wala. Dans *Helena et *Wala, l'hagiographe recommande les vertus sans les associer aux saints. Nous avons rangé les Vies d'après leur plus ancienne datation possible; un texte écrit vers 800 , comme *Bertuinus, figure donc parmi les sources du viII ${ }^{\mathrm{e}}$ siècle.

$15 *$ Amalberga, *Amantius, *Dodo, *Eusebia, *Lambertus Traiectensis [1, 2], *Paternianus, *Restituta, *Rictrudis, *Romanus, *Turiavus, *Ursmarus [2, 3, 4] (la prudence manque dans [4]), *Ursula. J.-C. PouLIN, L'idéal de sainteté dans l'Aquitaine carolingienne, d'après les sources hagiographiques (750-950) (= Travaux du Laboratoire d'histoire religieuse de l'Université de Laval, 1), Québec, 1975, mentionne à tort comme exemple la Vie de Gerbert d'Aurillac par Odon de Cluny.

16 *Adalbertus, *Ama, *Barlaam, *Bononius, *Egwinus (il manque la tempérance), *Emmerammus, *Fides, *Florentius, *Gerardus, *Gildas, *Gudila [1], *Iacobus (il manque la justice), *Liebertus, *Lucius, *Maiolus [1, 2], *Mauritius, *Modoaldus, *Odilo, *Oswaldus, *Petrus Trebanus, *Ragenufla, *Walaricus, *Walterius, *Wido, *Willelmus S. Benigni.

17 *Altmannus, *Augustinus [1, 2; dans 2, 1'auteur recommande les vertus sans les associer au saint], *Berardus, *Bernardus Claravallensis, *Bernardus Tironiensis, *Brigida (la justice manque), *Goswinus, *Gregorius VII [1, 2], *Gudila [2], *Hilarius Auciacensis, *Hugo, *Isidorus, *Lambertus Venciensis, *Lupus [2], *Malachias (le passage sur les vertus porte sur le prince Henri d'Ecosse; il manque par ailleurs la tempérance), *Magdalveus, *Mathildis, *Radegundis, *Richardus S. Vitoni, *Sacerdos, *Stephanus [1, 2], *Thomas Cantuariensis, *Victor, *Walfardus, *Willelmus Firmatus.

${ }^{18}$ Nous n'avons pu dater les Vies de Décorose $(\dagger 695)$ et de Tillon $(\uparrow 702)$; la Vie de ce dernier est postérieure de plusieurs siècles à sa mort. Il est également difficile de situer avec précision la composition de la Vie d'*Apianus, écrite entre les environs de 800 , quand le saint était vivant, et 1100, date approximative du manuscrit Vatican, Barb. 586, qui servit à l'édition des AASS.

${ }^{19}$ Nous avons vu toutes les Vies recensées sous le nom de Benoît dans la $B H L$ à l'exception du $n^{\circ} 1109$. Pourtant, Bruno de Segni ( $\left.\dagger 1123\right)$ associe Benoît aux vertus cardinales au cours d'un sermon prononcé peut-être au Mont Cassin: cf. Sententiae, VI.2: De confessoribus sermo 2, ed. PL 165, col. 1053B-C; voir aussi I. P. BEJCZY, Kings, Bishops and Political Ethics: Bruno of Segni on the Cardinal Virtues, in Mediaeval Studies, 64 (2002), p. 282. 
en outre, ces catalogues n'auraient pas connu de développements de telle sorte que certaines vertus auraient été préférées selon les époques ${ }^{20}$. Les chiffres que nous venons de présenter démentent cette théorie: les quatre vertus vont bel et bien ensemble dans l'hagiographie et elles constituent même un thème prisé au cours du Moyen Âge central. Le fait que les $\mathrm{XI}^{\mathrm{e}}$ et $\mathrm{XII}^{\mathrm{e}}$ siècles attestent un nombre équivalent de textes a d'ailleurs de quoi surprendre, puisque c'est seulement au $\mathrm{XII}^{\mathrm{e}}$ siècle que devait naître une attention systématique pour la vertu humaine, corrélativement à une réception intense des écrits moraux de l'Antiquité ${ }^{21}$. En ce qui concerne l'intérêt porté aux vertus cardinales, l'hagiographie du Moyen Âge central semble donc anticiper sur la littérature savante. Ajoutons pourtant que, malgré l'abondance apparente des références dans nos sources aux quatre vertus, leur mention reste très aléatoire pendant toute notre période. Ainsi, l'évocation des vertus dans un récit hagiographique ne garantit pas que les biographes postérieurs du même saint reprendront ce thème. Certes, on trouve des saints qui sont pourvus des vertus cardinales dans plusieurs de leurs Vies; pour Ursmer de Lobbes, nous avons ainsi pas moins de quatre attestations successives. La majorité des saints doivent cependant se contenter d'une seule mention. Même dans leurs adaptations directes de Vies préexistantes, les hagiographes du Moyen Âge ne reprennent pas souvent les passages sur les vertus cardinales: Alcuin supprime les références aux quatre vertus dans son remaniement de la Vie anonyme de Riquier; Pierre Damien fait de même dans sa Vie d'Odilon, un abrégé de l'ouvrage de Jotsald de Cluny où les quatre vertus constituent, comme nous le verrons, la base de la narration; et Pierre de Blois exclut les vertus cardinales dans sa Vie de Guthlac, modelée sur le récit de Félix de Jarrow ${ }^{22}$. Ceci est d'autant plus remarquable que ces trois auteurs traitent amplement $\mathrm{du}$ thème des quatre vertus dans leurs autres ouvrages; Alcuin et Pierre Damien ont même formulé au sujet des vertus cardinales les idées les plus intéressantes de leurs temps.

${ }^{20}$ L. HeRTLING, Der mittelalterliche Heiligentypus nach den Tugendkatalogen, in Zeitschrift für Aszese und Mystik, 8 (1933), p. 264. Une introduction bien plus instructive est fournie par GRÉGOIRE, Il libro ... (cf. supra, n. 13).

${ }^{21}$ Voir R. G. NEWHAUSER, The Treatise on Vices and Virtues in Latin and the Vernacular (= Typologie des sources du Moyen Age occidental, 68), Turnhout, 1993, p. 121-123. Les recherches entamées dans le cadre de notre projet «A Genealogy of Morals» ne peuvent que confirmer cette vision.

${ }^{22}$ Alcuin, Vita Richarii (BHL 7223-7227), ed. Chr. VEYRARD-COSME, L'cuvre hagiographique en prose d'Alcuin. Vitae Willibrordi, Vedasti, Richarii. Édition, traduction, études narratologiques (=Per verba, 21), Florence, 2003, p. 110-137; Pierre Damien, Vita Odilonis (BHL 6282), ed. PL 144, col. 925-944; Pierre de Blois, Vita Guthlaci (BHL 3728-3729), ed. C. Horstman, Nova Legenda Anglie, t. 2, Oxford, 1901, p. 698-719. 
Une deuxième constatation concerne la répartition géographique des saints en question. La grande majorité des saints et de leurs biographes figurant dans la première section de notre dossier viennent de la moitié nord de l'Europe, notamment des territoires de la Gaule situés au nord de la Loire, avec une forte concentration en Wallonie actuelle. Parmi les trente-cinq sources que l'on peut dater d'avant ou des environs de l'An Mil, on en compte vingt-six provenant vraisemblablement de la Gaule septentrionale, dont dix ou onze sont d'origine «belge» ${ }^{23}$. Cette prépondérance très nette existait déjà à l'époque mérovingienne: tous les textes des $\mathrm{VII}^{\mathrm{e}}$ et $\mathrm{VIII}^{\mathrm{e}}$ siècles, à une exception près, sont issus de régions situées au nord de la Loire ${ }^{24}$. La dominance «franco-belge» se poursuit dans les sources $\mathrm{du} \mathrm{XI} \mathrm{XI}^{\mathrm{e}}$ siècle $^{25}$ pour disparaître entièrement par la suite. Si les sources «françaises» abondent encore entre 1100 et 1200 , c'est désormais grâce à la participation croissante du $\mathrm{Midi}^{26}$. Nous croyons que ces chiffres traduisent l'émancipation culturelle de l'Europe du Nord vis-à-vis du monde méditerranéen. Rappelons que les vertus cardinales constituaient un élément typique du savoir philosophique de l'Antiquité. Le fait que dès le VII ${ }^{\mathrm{e}}$ siècle, bien avant la «Renaissance carolingienne», les quatre vertus sont intégrées dans l'hagiographie de l'Europe du Nord, démontre l'assimilation rapide de la culture intellectuelle de l'Empire romain par ces régions où la continuité directe avec l'Antiquité avait été plutôt faible. Les liaisons entre saints chrétiens et vertus gréco-romaines font entrevoir chez les hagiographes du Nord un effort pour créer une nouvelle civilisation sur la base des divers héritages culturels légués par les pays du Sud et du Moyen-Orient.

\footnotetext{
${ }^{23}$ Proviennent de la Gaule septentrionale: *Adalhardus, *Amalberga (B?), *Ansegisus, Audoenus, Bertuinus (B), Dodo (B), Droctoveus, Eligius, Eusebia, Eustadiola, Furseus, Helena, Lambertus Traiectensis [1, 2] (B), Lupus [1], Richarius, Rictrudis, Romanus, Silvinus (B), Trudo (B), Turiavus, Ursmarus $[1,2,3,4]$ (B), Wala. Le sigle (B) signifie que le saint est lié à un territoire situé dans l'actuelle Belgique. Notons que l'évêque Radbod d'Utrecht, auteur de la Vie d'Amalberge, était namurois de naissance, tandis qu'Eusébie et Rictrude sont originaires de la Flandre wallonne. Ajoutons que la Vie de Tillon, dont la datation et la provenance restent incertaines, pourrait également être rattachée à la Belgique, centre du culte du saint.

${ }^{24} \mathrm{La}$ liste de ces Vies est donnée ci-dessus, en n. 14; seul *Gregorius I fait exception (origine espagnole). *Guthlacus est d'origine anglaise, les autres Vies proviennent de la Gaule.

${ }^{25}$ Sources «belges»: *Gerardus, *Gudila [1], *Mauritius, *Modoaldus, *Ragenufla; on pourrait ajouter *Liebertus (Cambrésis) et *Oswaldus (Flandre française). Sources «françaises»: *Ama, *Fides, *Florentius, *Gildas, *Maiolus [1, 2], *Odilo, *Walaricus, *Walterius, *Willelmus S. Benigni.

${ }^{26}$ On ne compte plus qu'une Vie «belge» $\left({ }^{*}\right.$ Gudila [2]) - ou deux, si on y ajoute *Goswinus, d'origine artésienne - contre dix-sept ou dix-huit Vies «françaises». Parmi ces dernières, huit furent composées dans le Midi de la France: *Bernardus Claravallensis, *Bernardus Tironiensis, *Hugo, *Lambertus Venciensis, *Malachias, *Stephanus [1, 2], *Victor.
} 
Au-delà de cette concentration géographique, on peut discerner, de nouveau surtout avant l'An Mil, certaines filiations au caractère plus intime. Les vertus cardinales réapparaissent parfois dans les Vies de saints issus de la même famille, tels Rictrude et Eusébie (mère et fille), Adélard et Wala (deux frères, abbés successifs de Corbie, qui ont en outre un même biographe). Dans d'autres cas, les quatre vertus semblent passer, tel un héritage, de maître à disciple, notamment dans un environnement monastique: Ursmer de Lobbes, Cybard (Eparchius) et Éloi possédaient les vertus tout comme leurs adeptes respectifs Dodon, Amand et Tillon; Odilon de Cluny attribua les vertus à son prédécesseur Maïeul, tandis que son successeur Jotsald les associa à Odilon. Il ne s'agit pas forcément d'emprunts directs, car les passages en question ne correspondent pas littéralement. Par contre, le biographe de Gérard de Brogne s'est visiblement servi - et la constatation est bien nouvelle - de la Vie de Lambert de Maastricht composée par Étienne de Liège, l'oncle paternel de Gérard ${ }^{27}$. On peut par ailleurs signaler un emprunt étonnant, proche du plagiat. Guigues I $^{\text {er }}$ de Saint-Romain (1083-1136), cinquième prieur de la Grande Chartreuse, écrivit en 1134/1135 la Vie de Hugues de Grenoble en glorifiant l'observance des vertus cardinales de ce dernier: Si [laudatur] tolerantia, quis in tribulatione fortior? si justitia, quis districtior? si prudentia, quis circumspectior? si temperantia, quis moderatior? Près de quatre siècles plus tard, le prieur François Dupuy (1450-1521), successeur lointain de Guigues, recopia ce passage mot pour mot dans sa Vie de Bruno le Chartreux ${ }^{28}$, publiée en 1515 suite à l'autorisation papale de vénérer publiquement le fondateur de son Ordre, qui ne fut jamais formellement canonisé.

Troisième constatation: les hagiographes n'hésitent pas à attribuer les vertus cardinales aux femmes (phénomène plus impressionnant encore si on prend en compte les textes sur Marie). Certes, les saintes constituent

${ }^{27}$ Cf. ${ }^{*}$ Lambertus Traiectensis [2]: Erat ... insignitus prudentia, praeditus temperantia, fortitudine roboratus, justitia locupletatus; *Gerardus: excellentioribus pollebat virtutibus ... prudentia videlicet insignitus, temperantia redimitus, fortitudine roboratus, iustitia locupletatus. Sur cette dernière Vie, voir J. M. DE SMET, Recherches critiques sur la Vita Gerardi abbatis Broniensis, in Revue Bénédictine, 70 (1960), p. 5-61.

${ }^{28}$ François Dupuy, Vita S. Brunonis, I.22, ed. PL 152, col. 501B-C. Cf. Tituli funebres, 6.173: Bruno namque veram scientiam et prudentiam liberalium artium, necnon caeteras cardinales virtutes habuit et servavit, quas in bono fine consummavit (ed. ibid., col. 602B-C). Les Tituli funebres furent collectionnés par un chartreux de Calabre qui, voyageant en Italie et en France, fit inscrire sur son rouleau un bref éloge du saint défunt par chaque communauté visitée; voir Aux sources de la vie cartusienne, t. 1, La Grande Chartreuse, 1960, p. 19-24. Le titulus 6.173 fut ajouté par le monastère augustin Saint-Vincent à Nieul-sur-l'Autize (Vendée). 
une minorité dans notre recueil. Sur les trente-cinq Vies composées avant l'An Mil, sept seulement concernent une sainte; les $\mathrm{XI}^{\mathrm{e}}$ et $\mathrm{XII}^{\mathrm{e}}$ siècles, avec quatre exemples chacun, affichent même un certain déclin ${ }^{29}$. Mais la présence régulière des femmes est incontestable et, par rapport à l'Antiquité, elle offre une nouveauté. Dans le stoïcisme romain, les vertus cardinales avaient surtout figuré en tant que constituants de l'honnêteté dans la vie publique, domaine à peu près exclusivement masculin. Fidèle à la perspective stoïcienne, la Formula honestae vitae de l'évêque Martin de Braga $(† 579 / 580)$, bref traité sur les vertus cardinales très répandu au Moyen Âge et calqué probablement sur un ouvrage perdu de Sénèque, dessine le modèle de l'honnête homme (vir honestus) plutôt qu'elle ne s'intéresse à l'être humain en général ${ }^{30}$. L'ouverture des quatre vertus aux femmes, que l'on observe dans l'hagiographie (et plus tard dans la littérature savante du haut Moyen $\hat{A} g \mathrm{e}^{31}$ ), est une conséquence, à notre avis, de leur christianisation. En se déplaçant de la vie publique vers la vie religieuse et spirituelle, les vertus cardinales devaient forcément subir une neutralisation, étant donné que la religion s'adresse aux deux sexes. Hommes et femmes se préparent sur terre à la vie éternelle; saints et saintes possèdent donc les mêmes vertus, attributs d'une morale parfaite chez les élus du Seigneur.

Passant des statistiques au contenu, notons d'abord que toutes les biographies de saints écrites avant 1200 ne comportent pas de passages élaborés au sujet des quatre vertus. En règle générale, les hagiographes accordent les vertus cardinales à leurs saints avec un minimum de précisions ou même sans commentaire du tout; souvent, ils énumèrent les quatre vertus parmi nombre d'autres qualités morales, y compris parfois les vertus

${ }^{29}$ Avant 1000: *Amalberga, *Eusebia, *Eustadiola, *Helena, *Restituta, *Rictrudis, *Ursula; XI ${ }^{\mathrm{e}}$ : Ama, *Fides, *Gudila [1], *Ragenufla; XII ${ }^{\mathrm{e}}$ : *Brigida, ${ }^{*}$ Gudila [2], *Mathildis, *Radegundis.

${ }^{30}$ Ed. C. W. BARLOW, Martini episcopi Bracarensis opera omnia (= Papers and Monographs of the American Academy in Rome, 12), New Haven, 1950, p. 204-250. Voir par ex. c. 1: Singulae [sc. virtutes] ... honestum ac bene moratum virum efficiunt (p. 237); c. 6: hae quattuor virtutum species perfectum te facient virum (p. 247); c. 7: Magnanimitas autem si se extra modum suum extollat, faciet virum minacem inflatum... (p. 248).

${ }^{31}$ Jérôme, Epistula 66.3, ed. I. HILBERG (cf. supra, n. 13), p. 649-650, répartit les vertus entre quatre de ses amis, parmi lesquels trois sont des femmes: Paule (justice), Eustochium (courage), Pauline (tempérance); la prudence est représentée par Pammachius, destinataire de la lettre. Alcuin dédie son De ratione animae, traitant entre autres des quatre vertus, à Gundrade («Eulalie»), parente de Charlemagne. La première femme à mentionner les quatre vertus semble être Dhuoda, dans son Liber manualis ad filium suum Wilhelmum, prol. et 1.5, ed. P. RJCHÉ (= Sources Chrétiennes, 225), Paris, 1975, p. 76 et 106. Vers 1100, l'association des quatre vertus aux femmes devient fréquente. Nous espérons approfondir ce sujet dans une étude propre. 
théologales, les dons du Saint-Esprit ou les béatitudes ${ }^{32}$. Le catalogue des vertus qu'un auteur inconnu du VII ${ }^{\mathrm{e}}$ siècle incorpora dans sa Vie de Fursy est représentatif à plus d'un titre:

Erat enim forma praecipuus, corpore castus, mente devotus, affabilis colloquio, amabilis aspectu, prudentia praeditus, temperantia clarus, in interna fortitudine firmus, censura iustitiae stabilis, longanimitate largus, patientia robustus, humilitate mansuetus, caritate sollicitus, et ita in eum omnium virtutum decorem sapientia adornabat, ut secundum apostolum sermo illius semper in gratia sale esset conditus ${ }^{33}$.

Entre les $\mathrm{VIII}^{\mathrm{e}}$ et $\mathrm{XIII}^{\mathrm{e}}$ siècles, ce passage fut recopié plus ou moins intégralement dans pas moins de quinze Vies de saints (ce qui contredit la thèse selon laquelle chaque hagiographe inventait, entre 500 et 1200 , son propre catalogue des vertus ${ }^{34}$ ), sans compter les textes où plusieurs vertus cardinales font défaut ${ }^{35}$. Le biographe de Fursy a donc inauguré une véritable tradition hagiographique, dont les échos sont encore perceptibles au $\mathrm{XV}^{\mathrm{e}}$ siècle (voir notamment $*$ Meinulphus). Notons par ailleurs que Hugues de Flavigny inséra la liste dans son récit sur l'évêque Béranger de Verdun (r. 940-959) ${ }^{36}$. Ce récit fait partie de la grande chronique de Hugues, achevée en 1102, contenant un grand nombre d'autres notices biographiques sur les saints de la région; ces notices, dont plusieurs évoquent les vertus cardinales $^{37}$, sont recensées en partie dans $B H L$. Ceci n'est pas le cas pour son compte rendu de la vie de Béranger, qui ne fut jamais canonisé. Mais l'emprunt de la liste traditionnelle des vertus à l'hagiographie de l'époque prouve que pour Hugues de Flavigny, Bérenger comptait parmi les saints, à l'instar de tant d'autres évêques verdunois.

${ }^{32}$ Vertus théologales: *Amalberga, *Apianus, *Decorosus, *Gudila [1, 2], *Lambertus Traiectensis [2], *Lucius, *Maiolus [1], *Paternianus, *Ragenufla, *Ursmarus [2]; dons: *Emmerammus, cf. *Petrus Trebanus; béatitudes: *Maiolus [1].

${ }^{33}$ Le passage en romains s'inspire de Col. 4, 6 .

${ }^{34}$ Voir HERTLING, Der mittelalterliche Heiligentypus... (cf. supra, n. 20), p. 262, 264.

${ }^{35}$ Voir *Dodo, *Edmundus [1, 3], *Eustadiola, *Gudila [1, 2], *Guthlacus, *Hilarius Auciacensis, *Iacobus, *Ragenufla, *Romanus, *Ursmarus [1, 2], *Walaricus, *Willelmus S. Benigni. Les Vies anonymes de Mélaine de Rennes (BHL 5887), c. 3, ed. B. KRUSCH, in Monumenta Germaniae Historica. Scriptores rerum Merovingicarum, t. 3, Hanovre, 1896, p. 372 (IX s.), et de Procope de Sázava (BHL 6952), c. 1.15, ed. AASS, Iul. t. 2, p. $141 \mathrm{D}$ (XIV ${ }^{\mathrm{e}}$ s.), offrent deux exemples d'emprunts partiels à cet extrait, où seules deux vertus cardinales sont retenues.

${ }^{36}$ Hugues de Flavigny, Chronicon, ed. G. H. PerTz, in Monumenta Germaniae Historica. Scriptores, t. 8, Hanovre, 1848, p. 360.

${ }^{37}$ Voir *Gregorius VII [1], *Lupus [1], *Magdalveus, *Richardus S. Vitoni. Seuls les extraits du Chronicon relatifs à Magdalveus et à Richardus sont recensés dans la $B H L$. 
Dans certains cas, les propos du biographe de Fursy furent réarrangés. Ainsi, les Vies de Ragenufle et de Gudule en recèlent des adaptations qui correspondent entre elles mot pour mot, ce qui nous permet de relever (observation sans précédent dans la littérature savante selon nous) l'interdépendance de ces deux textes. La Vie de Ragenufle fut rédigée vers 1050, celle de Gudule vers 1100, sans que cette dernière soit forcément tributaire de l'autre: on sait qu'Hubert, le biographe de Gudule, a remanié un ancien texte aujourd'hui perdu; il est concevable que ce même texte ait servi de source pour la Vie de Ragnenufle, connue depuis longtemps pour son grand nombre de lieux communs empruntés à d'autres Vies de saintes mérovingiennes $^{38}$.

À ces mentions sommaires, majoritaires dans notre dossier, s'opposent les Vies qui parlent des vertus cardinales sans les lier à d'autres concepts ou qui reconnaissent même explicitement leur rôle privilégiée ${ }^{39}$. D'après ces dernières Vies, c'est par les quatre vertus que l'homme sera sauvé (*Richarius, ${ }^{*}$ Silvinus); elles portent l'homme au comble de ses possibilités (*Eligius) et déterminent la vie morale (*Rictrudis); elles sont considérées comme excellentes depuis l'Antiquité et elles incluent toutes les autres vertus (*Eusebia, cf. *Apianus); sans elles, personne ne peut parvenir à la sagesse (*Gildas); elles s'avèrent les qualités les plus utiles dans la vie humaine ( ${ }^{*}$ Gerardus); elles stimulent la plus parfaite harmonie dans l'homme et c'est par elles que l'être humain gagnera le ciel (*Thomas Cantuariensis); enfin, pour Alain de Lille, les vertus cardinales figurent sous la forme de quatre pierres précieuses sur la couronne qui symbolise la perfection de la vie terrestre et qui nous conduira à l'éternelle béatitude (*Augustinus [2]). À part ces déclarations quelque peu exaltées, plusieurs récits hagiographiques des $\mathrm{XI}^{\mathrm{e}}$ et $\mathrm{XII}^{\mathrm{e}}$ siècles évoquent l'image, courante dans les textes spirituels de l'époque, de la maison intérieure (qui se

${ }^{38}$ Voir L. VAN DER ESSEN, Étude critique et littéraire sur les Vitae des saints mérovingiens de l'ancienne Belgique (= Université de Louvain. Recueil de travaux publiés par les membres des conférences d'histoire et de philologie, 17), Louvain - Paris, 1907, p. 187-189 (Ragenufle), 297 (Gudule); Index Scriptorum Operumque Latino-Belgicorum Medii Aevi, II: XIf siècle, ed. P. FRANSEN - H. MARAITE, Bruxelles, 1976, p. 207-209 (Ragenufle); III: XII siècle, t. 1, ed. M. MCCORMICK - P. Fransen, Bruxelles, 1977, p. 77-78 (Gudule). Un résumé de la Vie perdue de Gudule est conservé dans les Gesta pontificum Cameracensium, 1.16, ed. L. C. BethmanN, in Monumenta Germaniae Historica. Scriptores, t. 7, Hanovre, 1846, p. 408.

${ }^{39}$ Nous ne pouvons donc entièrement souscrire à l'opinion de PoULIN, L'idéal de sainteté... (cf. supra, n. 15), p. 100: «les saints brillent tous par les mêmes vertus, accumulées sous forme de catalogues d'affirmations gratuites, sans illustrations concrètes... Les vertus sont naturellement fort en honneur; elles n'ont pas complètement éliminé la définition de la quadruple fontaine des vertus héritée de l'Antiquité, mais elles l'enserrent dans un réseau serré de vertus d'ascète et de moine»». 
réfère, bien entendu, à l'âme du croyant), dont les vertus cardinales constituent soit les quatre murs, soit les portes faisant face aux quatre vents (*Adalbertus, *Altmannus, *Egwinus, cf. *Petrus Trebanus).

Les passages que nous venons de citer montrent que les hagiographes n'évoquent pas les quatre vertus sans une implication pour leurs lecteurs. Dans la majorité des Vies de saints, les vertus cardinales se veulent exemplaires. Parfois, c'est le saint lui-même qui recommande les vertus (*Antonius [1, 2], *Barlaam, *Gildas, cf. *Ama) ${ }^{*}$; dans d'autres cas, c'est l'hagiographe. Au cours de son sermon sur Victor d'Arcis, Bernard de Clairvaux s'adresse même directement à son public (les Bénédictins de Montiéramey) dans un but pédagogique: les moines doivent prendre modèle sur Victor et sur sa pratique des vertus cardinales, sans toutefois vouloir imiter les aspects de sa vie hors d'atteinte pour la majorité des êtres humains. Seul l'auteur anonyme de la Vie d'Ouen (*Audoenus, IX ${ }^{\mathrm{e}}$ s.) semble mettre l'accent sur le caractère surnaturel des vertus des saints. Selon lui, le Tout-Puissant éclaire son Église de diverses lueurs, à l'instar du firmament; ses saints rayonnent tantôt par des miracles, tantôt par leur doctrine, le martyre ou la virginité; certains, enfin, brillent par la prudence, la justice, le courage et la tempérance. Nos vertus entrent-elles alors dans la sphère du miraculeux, se situant ainsi hors de portée des simples croyants? Nous avons du mal à le croire. À notre avis, l'hagiographe d'Ouen a voulu souligner que les qualités humaines des saints manifestent la grandeur divine tout autant que leurs miracles; autrement dit, la sainteté ne s'opère pas exclusivement par des merveilles, mais aussi par des comportements accessibles à tous. Sainteté admirable et sainteté imitable vont de pair $^{41}$. Même si le terme virtutes peut désigner les miracles aussi bien que les vertus ${ }^{42}$, les vertus cardinales, pour l'hagiographie du haut Moyen

40 * Ama constitue un cas particulier. Ici, c'est l'évêque Alpin de Châlons (un saint, présenté comme tel par l'hagiographe) qui, en consacrant Ame et ses sœurs à la vie religieuse, associe la virginité aux quatre vertus et incite les jeunes filles à bien retenir cette leçon.

${ }^{41}$ Voir A. VAUCHEZ, Saints admirables et saints imitables: les fonctions de l'hagiographie ont-elles changé aux derniers siècles du Moyen Age?, in Les fonctions des saints dans le monde occidental (III'-XIII siècle). Actes du colloque organisé par l'École française de Rome avec le concours de l'Université «La Sapienza) (Rome, 27-29 oct. 1988) (= Collection de l'École française de Rome, 149), Rome, 1991, p. 161-172, où l'auteur nuance son opinion antérieure selon laquelle les saints, jusqu'à la fin du XII siècle, apparaissaient surtout comme des êtres célestes, étrangers à la condition humaine et inimitables.

${ }^{42}$ Voir VAUCHEZ, La sainteté en Occident... (cf. supra, n. 5), p. 497 et suiv.; voir aussi S. AXTERS, Over Virtus en heiligheidscomplex onder de Merowingers, in Miscellanea historica in honorem Alberti De Meyer, t. 1 (= Université de Louvain. Recueil de travaux d'histoire et de philologie, $3^{\mathrm{e}}$ sér., 22), Louvain - Bruxelles, 1946, p. 266-285. 
Âge, ne constituent pas les ingrédients d'une sainteté surhumaine; qualités tangibles et imitables, elles marquent la perfection morale des croyants exemplaires qui se réjouissent de la grâce de Dieu.

\section{Les caractéristiques de la tradition durant le haut Moyen Âge}

L'intégration quasi totale des vertus cardinales dans le système des valeurs chrétiennes, qui caractérise l'hagiographie latine dès le début du Moyen Âge, mérite une plus ample analyse. À quel point peut-on distinguer, dans les sources de la période allant de 500 à 1200 , des conceptions antiques et chrétiennes, et comment s'intègrent-elles dans le discours hagiographique?

Notre plus ancien témoin du haut Moyen Âge, la Vie d'Hilaire d'Arles, présente déjà les vertus cardinales comme le moyen par excellence dont disposent les chrétiens pour vaincre les souillures terrestres et s'adonner au Seigneur. La justice nous apprend nos devoirs envers Dieu, la prudence nous enseigne à suivre les exemples des saints, la tempérance nous incite à ériger un temple au Tout-Puissant par l'abandon des vices. Par contre, le courage se caractérise ainsi:

Fortitudo cordis animae generosae, nihil humile, nihil abiectum permittit arripere; celsa sectari, ardua conscendere facit, adversa superare, desperationem fortibus probationem nullatenus exhibere permittens ${ }^{43}$.

Le courage semble avoir conservé, plus clairement encore que dans le De excessu fratris d'Ambroise de Milan, sa connotation païenne de fierté aristocratique qui fait mépriser le danger dans les épreuves aussi bien que le vil quotidien; son sens religieux réside dans son but ultime Dieu et la vie éternelle - plutôt que dans ses effets directs. Ce qui frappe surtout, c'est l'opposition explicite que construit l'hagiographe entre le courage et le humile. Sous l'influence de Grégoire le Grand notamment, l'humilité figurait dans la littérature morale du haut Moyen Âge en tête des vertus chrétiennes. Au XIII ${ }^{\mathrm{e}}$ siècle, les théologiens forgèrent une synthèse entre l'humilité et la magnanimité, élément principal de la fortitudo et souvent son synonyme ${ }^{44}$. Il est évident que la Vie d'Hilaire reste loin de cette synthèse, tout comme deux autres Vies du haut Moyen Âge qui associent le courage des saints à l'affrontement des périls dans un envi-

${ }^{43} *$ Hilarius Arelatensis [p. 85].

${ }^{44}$ Voir R. A. GAUTHIER, Magnanimité: l'idéal de la grandeur dans la philosophie païenne et dans la théologie chrétienne (= Bibliothèque thomiste, 28), Paris, 1951; C. CASAGRANDE - S. VECCHIO, Histoire des péchés capitaux au Moyen Âge (= Coll. historique), Paris, 2003, p. 36-44. 
ronnement hostile (*Amantius, *Eligius). Le portrait du missionnaireaventurier réalisant des exploits pour la foi dans un monde sauvage qu'il parvient finalement à soumettre est très répandu durant le haut Moyen Âge; les Vies d'Éloi et d'Amand de Boixe ennoblissent cette attitude en l'associant à la vertu cardinale du courage. L'hagiographe présumé d'Amand, Hugues d'Angoulême, ajouta dans ce but ses propres remarques à un passage emprunté à Isidore de Séville, qui favorisait plutôt une conception stoïcienne de cette vertu ${ }^{45}$. Dans ces deux Vies, l'héroïcité de la vertu l'expression n'existait pas encore ${ }^{46}$, mais l'idée était bien là — réside dans la bravoure plutôt que dans l'humilité ${ }^{47}$. Les savants de l'époque avaient beau avertir que la vertu du courage avait peu en commun avec la témérité (opinion que Marbode de Rennes répète dans sa Vie de Florent du Mont Glonne $^{48}$ ), le Moyen Âge ne perdit jamais son admiration pour la hardiesse qui servait la cause de Dieu; aussi, les martyrs passaient-ils depuis l'époque des Pères pour les représentants par excellence de la fortitudo ${ }^{49}$.

45 *Amantius, c. 4 [p. 334-335]: Fortitudo cum eo erat animi magnitudine, contemptu divitiarum. In adversis aut patienter videbatur cedens aut fortiter resistens. Nullis emolliebatur illecebris; adversis non frangebatur, non elevabatur secundis. Invictus eminebat ad labores, fortis ad pericula. Pecuniae neglector, avaritiam fugiebat. Contra improbos ad periculum animum praeparans, molestiis nullis cedebat. Gloriae cavebat appetitus ... in fortitudine vim virtutis habebat metumque mortis contemnebat, et si immineret persecutoris gladius, primus mori pro Christo tormentis subjectus gauderet: ob eam causam Hiberonum partes penetrare nisus est (passage repris, avec des variantes de forme, d'Isidore, De differentiis rerum, 157, ed. PL 83, col. 95A-B; Hugues ajouta les propos imprimés ici en caractères romains).

${ }^{46}$ D'après VAUCHEZ, La sainteté en Occident... (cf. supra, n. 5), p. 607, l'expression figure dans les documents pontificaux depuis 1347; sur les opinions des scolastiques, voir A. ESZER, $I l$ concetto della virtù eroica nella storia, in Sacramenti, liturgia, cause dei santi. Studi in onore del cardinale G. Casoria, ed. A. MORONI et al., Naples, 1992, p. 605-636; pour l'époque moderne, voir P. GIOVANNUCCI, La virtù eroica nei processi di canonizzazione dell'età moderna: prolegomeni ad una ricerca, in Ricerche di storia sociale e religiosa, 32 (2003), p. 181-193. L'expression apparait une fois dans notre recueil (*Catharina Senensis [1] [col. 1249]; cf. infra, p. 347).

${ }^{47}$ Voir notamment *Eligius [col. 519D]: Quid fortius, qui inter Francorum protervam gentem barbarasque nationes, et arrogantium probrosas contumelias spiritum semper servavit invictum? La phrase suivante souligne pourtant l'humilité du saint: Quid temperantius qui nobilium felicitate spreta, maluit in humilioribus tuto gressu pergere, quam pendulo gradu in sublimibus fluctuare? Sur la continuité des valeurs prédominantes chez les élites de la Gaule antique et médiévale, voir M. HEINZELMANN, Bischofsherrschaft in Gallien. Zur Kontinuität römischer Führungsschichten vom 4. bis zum 7. Jahrhundert. Soziale, prosopographische und bildungsgeschichtliche Aspekte (= Beihefte der Francia, 5), Munich, 1976.

48 *Florentius, c. 2.16 [p. 435D]. Mais Marbode de souligner: Qui autem pro veritatis assertione pericula et labores non tantum suscipit et tolerat, sed etiam anticipat et amplexatur, hic non fortis, sed fortissimus etiam est vocandus.

${ }^{49}$ Pour l'association aux martyrs du courage en tant que vertu cardinale, voir par ex. Bruno de Segni, Sententiae, II.4, ed. PL 165, col. 912C-913A; Alain de Lille, De arte praedicatoria, 24, ed. PL 210, col. 160A; Thomas d'Aquin, Summa theologiae, II.II.124.2, Opera omnia (édition léonine), t. 10, Rome, 1899, p. 28-29. 
L'exemple favori du Moyen Âge, remontant à Ambroise de Milan, était Laurent, qui dit à son bourreau depuis le gril où il brûlait: «C'est rôti, retourne et mange» ${ }^{50}$.

Dans d'autres Vies, par contre, le courage s'identifie principalement au combat du saint contre ses propres vices et les tentations du diable. Cette interprétation du courage se rencontre bien plus fréquemment dans l'hagiographie médiévale que la connotation de hardiesse, mais seulement jusqu'au XII ${ }^{\mathrm{e}}$ siècle; après, elle disparaît presque entièrement ${ }^{51}$. Était-elle liée à la production hagiographique des Bénédictins? Selon les principes qui dirigent la vie monastique, les ennemis les plus redoutables du chrétien sont assurément ceux qui résident à l'intérieur de son âme. Mais pourquoi les Bénédictins et les hagiographes des autres Ordres religieux n'auraientils pas continué la tradition après 1100 ? Il semble que vers le XII siècle, la vertu de tempérance ait repris et englobé la connotation combative du courage dans l'hagiographie. Un nombre croissant de Vies présentent la tempérance du saint au travers de la mortification du corps. La vertu se manifeste dans la répression des instincts reproductifs et nutritifs, et par conséquent dans l'observation de la chasteté, de la sobriété et de la frugalité $^{52}$; certaines Vies remplacent le terme temperantia par abstinentia ou sobrietas, ou bien par des circonlocutions illustrant l'ascèse du saint ${ }^{53}$. Ces changements d'interprétations peuvent s'expliquer par l'intérêt nouveau $\mathrm{du} \mathrm{XII}^{\mathrm{e}}$ siècle pour la littérature morale de l'Antiquité. Chez les auteurs antiques, la répression des mauvais désirs faisait déjà partie de la tempérance. Vers le $\mathrm{XII}^{\mathrm{e}}$ siècle, l'hagiographie semble s'être rapprochée quelque peu de l'ancienne conception des vertus cardinales, en assignant à la tempérance la lutte contre le corps et en redéfinissant le courage, suivant Macrobe, comme la capacité à supporter la misère tout comme la pros-

${ }^{50}$ Ambroise, De officiis, 1.41.207, ed. M. TESTARD (cf. supra, n. 8), p. 78; trad. ID. (= Collection des Universités de France), Paris, 1984, p. 197. L'anecdote fut répétée pour exemplifier le courage dans nombre d'exposés sur les vertus cardinales, par ex. chez Pierre le Mangeur, Sermo 36, ed. PL 198, col. 1809A, et dans la source directe de ce dernier, la Summa 'Abel' (inédite) conservée dans le ms. Paris, B.N.F., lat. 10633, f. 134'.

${ }^{51}$ Voir *Ama, *Amantius, *Apianus, *Emmerammus, *Florentius (sur ce cas spécial, cf. infra, p. 333), *Maiolus [1], *Walterius; dans *Turiavus et *Wala, ainsi que dans *Notkerus $\left(X^{\prime} V^{e}\right.$ s.) et *Ursulina $\left(X V^{e} \mathrm{~s}\right.$. $)$, chacune des quatre vertus aide le saint à combattre ses vices.

${ }^{52}$ Notamment *Florentius, c. 2.14 [p. 435A]; *Lupus [2], *Petrus Trebanus, *Thomas Cantuariensis, *Wido; au XIII ${ }^{e}$ s.: *Petrus Monoculus; au XV' s.: *Bernardinus, c. I.4 [p. 278A] et *Catharina Senensis [1] [col. 1248].

${ }^{53}$ Abstinentia / sobrietas: *Magdalveus, *Trudo. Description de l'ascèse: *Walterius [p. $702 \mathrm{C}]$ et, au XIII ${ }^{\mathrm{e}}$ s., ${ }^{*}$ Richardus Cicestrensis. 
périté $^{54}$ - ou bien, selon une formule alternative remontant à Augustin et populaire dans l'hagiographie jusqu'à la fin du Moyen Âge: l'être humain a besoin de fortitudo in adversis, temperantia in prosperis ${ }^{55}$. Trois sources remplacent fortitudo par constantia (*Droctoveus, *Isidorus, *Mauritius), ce qui pourrait trahir une influence stoïcienne. Quant à la justice et la prudence, les connotations antiques et chrétiennes se confondent facilement: la justice s'exprime tantôt dans la reconnaissance des devoirs devant Dieu (*Hilarius Arelatensis, *Lambertus Venciensis, *Maiolus [1], *Rictrudis, *Thomas Cantuariensis; au XIII ${ }^{\mathrm{e}}$ siècle: *Petrus Monoculus) ou dans l'assistance aux pauvres (*Eligius, ${ }^{*}$ Elisabeth $^{56}$ ), tantôt dans les capacités politiques (*Adalhardus, *Berardus, *Oswaldus, cf. *Apianus) qui se trouvent parfois christianisées lorsque le saint utilise son pouvoir avant tout pour aider les humbles contre leurs oppresseurs. Quelquefois, c'est plutôt par la prudence que le saint traduit ses obligations envers le Seigneur ${ }^{57}$ et renonce au péché (*Walterius, cf. *Augustinus [2]), conformément à l'antithèse paulinienne entre prudentia mundi et prudentia spiritus (Rom. 8,6)

${ }^{54}$ Macrobe, Commentarii in somnium Scipionis, 1.8.7, ed. M. ARMISEN-MARCHETTI (= Collection des Universités de France), Paris, 2003, p. 51 : [est] fortitudinis animum supra periculi metum agere nihilque nisi turpia timere, tolerare fortiter uel adversa uel prospera. Cf. *Eusebia: fortitudo in adversantibus sive prosperis; *Lambertus Venciensis: Fortis erat, quia numquam adversis potuit frangi, nec aliquando prosperis elevari; *Rictrudis: per fortitudinem nec illecebris emolliri, nec adversis frangi poterat; *Wido: fortitudo ... ex eo dignoscitur, quod nullis umquam fractus incommodis, nullisve carnis cessit illecebris.

${ }^{55}$ Augustin, Epistula 244, ed. A. GolDBACHER (= Corpus Scriptorum Ecclesiasticorum Latinorum, 57), Vienne - Leipzig, 1911, p. 581: qui [Christus] non solum aeterna sapientia sed etiam humana praesentia docuit nos temperanter prospera saeculi huius contemnere et fortiter aduersa tolerare. Cf. *Gregorius VII [2]: in adversis fortem, in prosperis temperatum; *Petrus Trebanus: temperantia a dextris, fortitudo a sinistris. Nam ... quae sunt a dextris, sunt prospera: quae sunt a sinistris, adversa; *Restituta, 2.11 [p. 195]: per fortitudinem adversa aequanimiter tolerantur, per temperantiam fluxa voluptas libidinis refraenatur; *Thomas Cantuariensis: Fortitudo, quae eum in adversis vindicans ... Temperantia, quae eum in prosperis nihil immoderate facere permittens... Pour le bas Moyen Âge, voir *Catharina Senensis [2] [p. 16]: prosperitates cum temperantia moderandas ... adversitates cum patientia tollerandas; *Hildegardis: in adversis vinceret, per fortitudinem; illecebrosis non cederet, per temperantiam; *Ursulina: fortis in adversis, temperata in prosperis fuit ... temperate prosperis utebatur, fortiter adversa tolerabat; *Waldburgis: fortitudini innitebatur in adversis, temperantia ... regebatur in quibuscumque prosperis.

${ }^{56}$ L'inspiration augustinienne de l'idée est évidente, mais la formule d'*Elisabeth, Est autem effectus iustitie miseris subvenire, effectus prudentie insidias precavere, effectus fortitudinis temporis molestias perferre, effectus temperantie illecebras refrenare, semble remonter à Pierre de Poitiers; cf. E. LIo, Il testo di S. Agostino "justitia <est> in subveniendo miseris" in Pier Lombardo e nei suoi glossatori fino a S. Tomasso d'Aquino, in Miscellanea lombardiana, Novare, 1957, p. 186.

${ }^{57}$ Voir *Ama, *Apianus, *Lambertus Venciensis, cf. *Florentius, *Rictrudis; au $\mathrm{XV}^{\mathrm{e}} \mathrm{s}$., *Catharina Senensis [1]. 
et au rejet de la sagesse de ce monde $(1 \text { Cor. } 3,19)^{58}$. Pourtant, la prudence se définit le plus souvent dans l'hagiographie par le commandement de la raison, tout comme dans l'Antiquité.

L'assimilation des vertus cardinales au christianisme n'est pas un phénomène isolé dans l'hagiographie du haut Moyen Âge. Dans la plupart des genres littéraires florissant avant l'An Mil, les références aux quatre vertus - le plus souvent très brèves d'ailleurs - sont légion, même dans l'exégèse: chaque fois qu'apparaît dans la Bible une série de quatre éléments (les fleuves du Paradis, les coins du Temple de Salamon, etc.), les commentateurs la mettent en rapport avec un maximum d'autres quatuors sacrés, y compris les vertus cardinales. La polémique avec la philosophie païenne est à peu près absente chez ces auteurs; la plupart d'entre eux semble même ignorer qu'une telle polémique ait existé aux temps des Pères, la diffusion du De officiis d'Ambroise de Milan étant restée extrêmement faible ${ }^{59}$. Vu ces circonstances, il est assez remarquable que deux Vies de saints composées au $\mathrm{x}^{\mathrm{e}}$ siècle s'opposent explicitement à la conception ancienne des vertus. La Vie d'Amand de Boixe reprend un passage d'Isidore de Séville (qui s'était inspiré, pour sa part, d'Augustin) portant sur l'antithèse stoïcienne entre les vertus cardinales et les quatre affections metus, cupiditas, gaudium et dolor. Les «philosophes» considéraient ces affections comme les quatre vices principaux, assure l'hagiographe, mais Amand savait, de même que de nombreux autres saints, qu'elles constituaient des media moralement neutres que la libre volonté peut transformer en vices aussi bien qu'en vertus ${ }^{60}$. Notre deuxième exemple, la Vie de Restitute attribuée au sous-diacre Paul de Naples, offre un exemple concret de véritable polémique. Lorsque Restitute, martyre africaine, comparaît devant son juge romain, celui-ci veut se montrer homme raisonnable en soulignant que les lois sacrées de 1'Empire ordonnent aux juges de respecter les vertus cardinales pour éviter de se laisser

${ }^{58}$ Voir *Eligius [col. 519D]: Quid enim eo prudentius, qui contempta mundi stultitia Christum secutus est, Dei virtutem et Dei sapientiam?

${ }^{59}$ Voir S. MÄHL, Quadriga virtutum. Die Kardinaltugenden in der Geistesgeschichte der Karolingerzeit (= Beihefte zum Archiv für Kulturgeschichte, 9), Cologne, 1969, p. 35-49 (sur l'exégèse); introduction de M. TESTARD dans Ambroise, De officiis (cf. supra, n. 8), p. XIII-XIX (sur l'influence de l'ouvrage). $\mathrm{M}^{\text {lle }}$ Jasmijn Bovendeert prépare une thèse de doctorat sous ma direction sur les vertus cardinales dans la pensée chrétienne de l'Occident avant l'An Mil.

${ }^{60} *$ Amantius, c. 4 [p. 334-335]; cf. Isidore, De differentiis rerum, 159-160, ed. PL 83, col. 95; Augustin, De civitate Dei, 14.9, ed. B. DomBART - A. KalB (= Corpus Christianorum. Series Latina, 48), Turnhout, 1955, p. 425-430. Voir aussi *Petrus Trebanus [p. 642A-B]: Justitia namque dirigit spem; prudentia mitigat dolorem; temperantia format gaudium; fortitudo confortat timorem. 
diriger par la colère. Plus tard, pendant son procès, la sainte prend sa revanche en lançant à son juge toute une série de récriminations. Comment le juge peut-il se vanter de respecter les vertus cardinales - Restitute en donne les définitions courantes de la philosophie stoïcienne -, alors qu'il préfère la terre et le diable au ciel et aux anges, tout en méconnaissant la source de la vraie sagesse? Que le juge se hâte d'accepter la foi: toute sa sagesse et toute sa culture actuelles reposent sur les ruses du diable et le mèneront aux flammes éternelles ${ }^{61}$. Voilà une belle dramatisation de l'ancien conflit entre vertus classiques et chrétiennes - mais on ne saurait en trouver un autre exemple dans l'hagiographie médiévale ${ }^{62}$. En règle générale, les quatre vertus s'intègrent sans problème dans les Vies de saints et s'avèrent même des vecteurs authentiques de la moralité chrétienne.

Afin d'étayer cette dernière thèse, étudions maintenant de plus près quelques sources qui mettent les vertus cardinales particulièrement en relief. La Vie d'Odilon de Cluny, composée en 1051/1052 par son élève Jotsald, est la première biographie de saint (et même la première biographie médiévale tout court) à employer les quatre vertus comme principes structurants de la narration. Plutôt que de figurer parmi les ingrédients d'une sainteté préétablie, les quatre vertus servent de catégories principales — à côté des miracles, bien entendu — dans lesquelles la sainteté se conçoit. Le premier livre de l'œuvre se concentre entièrement sur les vertus du saint, le second livre étant consacré aux miracles: organisation qui préfigure celle des Vies de saints et des dossiers de canonisations aux Temps Modernes. D'après Jotsald, la prudence d'Odilon prévaut dans toutes ses activités intellectuelles: elle se comprend comme une soif de connaissances, notamment de connaissances sacrées (c. 1.5). Par la justice, qui rend à chacun son dû, Odilon se faisait aimer par les gens de toutes conditions, mais surtout par les hauts dignitaires ecclésiastiques et séculiers qui frayaient avec lui d'égal à égal, comme le raconte l'hagiographe avec force détails (c. 1.6). La fréquentation de la haute société est-

${ }^{61}$ Sur l'attribution de *Restituta à Paul de Naples, voir P. DEVos, Deux œuvres méconnues de Pierre sous-diacre de Naples au $X^{2}$ siècle: la Vie de S. Grégoire le Thaumaturge et la Passion de $S^{\text {te }}$ Restitute, in $A B, 76$ (1958), p. 350-353.

${ }^{62}$ Dans *Helena, Alman de Hautvillers loue les chrétiens qui, imprégnés des quatre vertus, comprirent que la vie ne finit pas avec la mort, comme le croyaient les philosophes grecs, mais qu'elle commence après la mort. Pourtant, malgré sa référence à «Platon», Alman n'attaque pas la conception grecque des vertus: Viderunt hoc illi, quibus Deus clementiae suae dono tales esse concessit, quibus ascenderet fons de terra irrigare paradisum, quique referti tetrasti virtutum principalium, ac si donati ubertate quatuor fluminum in intelligibili forma, velut in Platonica idea numero immortali quadraverunt seipsos; et ut fonte de terra ascendente pervenirent ad fontem in caelis regnantem, purgatione intima et fide robustissima certaverunt. 
elle une marque de justice? Pour Jotsald, oui: il reconnaît avant tout en son ancien supérieur un monarque juste et miséricordieux, comme le montrent également les chapitres suivants qui cherchent à mettre en lumière la vertu de justice dans la vie du saint. Odilon se montrait généreux envers les pauvres; à savoir, il les faisait soigner par ses subordonnés (c. 1.7), sans se salir personnellement les mains. Ayant trouvé les corps abandonnés de deux jeunes défunts, il les fit habiller et enterrer (c. 1.8) œuvre de piété, certes, mais ici encore accomplie par l'intermédiaire de ses subordonnés. Lorsqu'un ecclésiastique frappé par la lèpre lui demanda humblement, par l'intermédiaire d'un messager, un entretien (ut ad se accedat, humiliter rogat per internuntium), Odilon daigna accepter (Quod sanctus facere non recusavit, recolens dominice humilitatis exemplum) et lui fit même l'accolade, au grand étonnement de tous les moines présents (c. 1.9, p. 163-164) - geste emblématique, au Moyen Âge, de la miséricorde royale. Finalement, le saint aimait bien accueillir les visiteurs; pour ses propres moines, il était comme un père, capable de réunir les gens les plus divers sous son règne bienveillant (c. 1.10). La description de la fortitudo nous rappelle qu'Odilon était moine plutôt que roi: cette vertu se manifestait chez lui par la patience et par une ascèse sévère (1.11). Quant à la tempérance, Jotsald semble avoir du mal à l'intégrer dans son récit. Il se contente d'assurer qu'Odilon gardait une juste mesure en tout: dans le soin de son aspect extérieur, dans la correction des fautes et même dans ses jeûnes (1.13) - observation qui s'accorde assez mal avec le chapitre précédent relatant l'habitude du saint de châtier violemment son corps.

Notre analyse suggère que dans sa Vie d'Odilon, Jotsald a voulu réunir deux modèles, celui du roi juste et celui du serviteur héroïque de Dieu, avec les deux systèmes de valeurs différentes qui y correspondent. Le choix de l'hagiographe pour le schème des vertus cardinales, liées à la vie publique dans l'Antiquité romaine et accordées aux saints dans l'hagiographie médiévale, devient alors compréhensible. Notons que Jotsald a emprunté ses définitions des quatre vertus, attribuées par lui aux philosophi, non seulement à Ambroise de Milan, comme le signale l'édition critique de la Vie, mais aussi à la littérature classique: c'est du commentaire de Macrobe sur le Somnium Scipionis que le clunisien a repris sa définition de la fortitudo ${ }^{63}$, même si sa présentation de cette vertu rappelle plutôt les valeurs de la vie monastique.

63 * Odilo c. 1.11 [p. 167] (sans identification de la source): Fortitudo est animum supra periculi metum agere nihilque nisi turpia timere, tolerare fortiter adversa vel prospera $=$ Macrobe, Commentarii..., 1.8.7, ed. M. ARMISEN-MARCHETTI (cf. supra, n. 54), p. 38. 
La concentration sur le rôle quasi monarchique du saint, moralement élevé à l'aide des vertus cardinales, se manifeste encore plus clairement dans la Vie d'Adélard de Corbie, ouvrage de Paschase Radbert (ca 790859), ainsi que dans la Vie de l'évêque Bérard des Marses, composée après 1130 par un de ses disciples. Contrairement à Odilon, Adélard et Bérard étaient des figures publiques dans le sens propre, comme le soulignent leurs hagiographes. Adélard servit à deux reprises comme protecteur de l'Italie au nom de son cousin Charlemagne. C'est dans ce contexte politique que Paschase introduit les vertus cardinales. Par sa prudence, Adélard s'avéra un conseiller sans rival, tandis que son sens de la justice dominait l'exercice de ses fonctions politiques: incorruptible, il rendait ses jugements sans acception de personnes, en brisant le pouvoir illégitime des forts et en rétablissant les droits des humbles. Comme devait le faire Jotsald, Paschase accentue donc surtout la justice de son héros, vertu qui s'affirme dans une position d'autorité et de pouvoir; les allusions à Cicéron dans ce contexte sont d'ailleurs patentes ${ }^{64}$. Quant à Bérard, le pape Pascal II lui confia le gouvernement de la Campanie. Comte de la province, il excellait dans la pratique des quatre vertus, souligne son biographe: il régnait avec prudence, poursuivait implacablement les malfaiteurs et leurs vices grâce à sa justice et son courage, et gardait la tempérance en respectant la juste mesure dans toutes ses actions.

Dans ces deux cas, les vertus cardinales n'illustrent pas tant la vie spirituelle que les dons politiques du saint; on aurait pu louer n'importe quel roi juste en termes identiques. On pourrait croire que le contexte public explique le recours des deux hagiographes aux vertus cardinales, caractéristiques de l'esprit public dans le stoïcisme romain. Pourtant, les allusions aux auteurs stoïciens latins font défaut dans la Vie de Bérard, tandis qu'elles sont évidentes dans la Vie de Florent, ermite du Mont Glonne en Anjou. D'après l'auteur, Marbode (1035-1123), écolâtre à Angers jusqu'à son accession à l'évêché de Rennes en 1096, Florent possédait toutes les vertus; étant donné qu'elles se résument dans les quatre vertus principales, celles-ci feront l'objet de son attention, et leur exposé forme l'une des trois parties de son ouvrage. Traitées une à une, les vertus sont présentées à l'aide des définitions qu'en donna Cicéron dans son $D e$

${ }^{64} \mathrm{Cf} .{ }^{*}$ Adalhardus [col. 1517A] (à propos de la prudence du saint): Cernebat enim simul praeterita, praesentia et futura; et Cicéron, De inventione 2.53.160, ed. E. STRÖBEL (cf. supra, n. 10), p. 146 (sur les trois composantes de la prudence): memoria est, per quam animus repetit illa, quae fuerunt; intellegentia, per quam ea perspicit, quae sunt; providentia, per quam futurum aliquid videtur ante quam factum est. Par ailleurs, *Adalhardus c. 20 [col. 1518C], cite le De inventione de façon explicite. 
inventione; ensuite, l'hagiographe explique comment elles se manifestaient dans la vie du saint angevin. Au cours de son exposé, Marbode développe d'ailleurs une idée qui devait exercer une influence considérable sur la doctrine des vertus au XII ${ }^{e}$ siècle. Tous les vices proviennent soit ex cupiditate, soit ex timore (c'est-à-dire l'appréhension du danger, de la peine et de la mort). Or, la tempérance sert à vaincre la cupidité, et le courage à dominer les peurs; ensemble, ces deux vertus dissipent donc les vices et soutiennent ainsi la justice ${ }^{65}$. Au XII ${ }^{\mathrm{e}}$ siècle, Pierre Abélard et ses élèves devaient reprendre cette idée qui, en outre, se diffusa largement grâce à son insertion dans le célèbre Moralium dogma philosophorum ${ }^{66}$. Mais la paternité de l'idée revient au savant angevin, et c'est ici qu'elle est reconnue pour la première fois; de fait, la méconnaissance de cette paternité a même influencé le débat toujours indécis sur l'origine du Moralium $\operatorname{dog} m a^{67}$. Le succès qu'eut la conception de Marbode constitue l'un des rares exemples où il est possible de démontrer l'influence de l'hagiographie sur les théories de la morale au Moyen Âge ${ }^{68}$.

$65 *$ Florentius, 2.15 [p. 435C].

${ }^{66}$ Voir Pierre Abélard, Collationes, c. 120, ed. J. MARENBON - G. ORLANDI ( $=$ Oxford Medieval Texts), Oxford, 2001, p. 136; Sententiae Abaelardi [= Sententiae Hermanni = Epitome theologiae christianae], c. 32, ed. PL 178, col. 1751B-1752C; Sententie Parisienses, ed. A. LANDGRAF, Écrits théologiques de l'École d'Abélard (= Spicilegium sacrum Lovaniense, 14), Louvain, 1934, p. 53; Ysagoge in theologiam, ed. ibid., p. 75; Commentarius Cantabrigiensis in epistolas Pauli e schola Petri Abaelardi, ed. A. LANDGRAF (= Publications in Mediaeval Studies, 2), t. 2, Notre Dame, 1939, p. 295-296; Das Moralium dogma philosophorum des Guillaume de Conches, ed. J. HOLMBERG (= Arbeten utgivna med understöd av Vilhelm Ekmans Universitetsfond, Uppsala, 37), Uppsala, 1929, p. 8.

${ }^{67}$ Le texte a été respectivement attribué à Guillaume de Conches (par son éditeur et $\mathrm{Ph}$. Delhaye), à Gautier de Châtillon (par R. Gauthier) et à Alain de Lille (par P. Glorieux); pour un aperçu du débat, voir J. R. WILliams, The Quest for the Author of the Moralium Dogma Philosophorum, in Speculum, 32 (1957), p. 736-747. D'après R. GAUTHIER, Les deux recensions du Moralium dogma philosophorum, in Revue du Moyen Âge latin, 9 (1953), p. 234-235, l'auteur du Moralium dogma reprit l'idée sur le rôle du courage et de la tempérance de l'Ysagoge ou d'un autre texte issu de l'École d'Abélard; J. MARENBON, Abelard's Ethical Theory: Two Definitions from the Collationes, in From Athens to Chartres: Neoplatonism and Medieval Thought. Studies in Honour of Édouard Jeauneau, ed. H. J. WESTRA (= Studien und Texte zur Geistesgeschichte des Mittelalters, 35), Leyde, 1992, p. 306, n. 6, et ID., The Philosophy of Peter Abelard, Cambridge, 1997, p. 286, n. 9, souscrit à cette opinion. Il est pourtant concevable que l'auteur se soit directement inspiré de l'ouvrage de Marbode.

${ }^{68}$ Un autre exemple, bien moins spectaculaire, est fourni par Alain de Lille, De virtutibus et de vitiis et de donis Spiritus sancti, ed. O. LOTTIN, Psychologie et morale aux XII et XIII siècles, t. 6, Gembloux, 1960, p. 67-68. Traitant le problème de la connexion des vertus, Alain se réfère à l'observation suivante sur Brice, successeur de Martin de Tours: In uita beati Britii legitur quod quamuis superbus esset et uanus, castus tamen habebatur in corpore (cf. Grégoire de Tours, Libri historiarum, 2.1, ed. B. KRUSCH - W. LEVISON, in Monumenta Germaniae Historica. Scriptores rerum Merovingicarum, t. 1.1, Hanovre, 1937-1951, p. 37). Alain croit à cette connexion et explique ainsi les paroles de Grégoire: Quod de beato Britio legitur quod 
Malgré les citations évidentes des auteurs classiques - en forgeant son idée sur le rôle du courage et de la tempérance, Marbode eut sans doute recours à Sénèque et peut-être également à Cicéron ${ }^{69}-$, la Vie de Florent pourvoit toutes les vertus cardinales, y compris la justice, d'une explication religieuse. Rendre à chacun son dû signifiait pour Florent attribuer les vices à soi-même et le bien à Dieu; dès lors, la justice engendre l'humilité, sans laquelle les vertus cardinales perdent toute leur valeur ${ }^{70}$. Conçue ainsi, la justice n'a plus rien à voir avec la vie publique, que l'ermite angevin fuyait de toute façon. L'utilisation dans l'hagiographie de sources classiques portant sur les vertus cardinales ne veut donc pas dire que le saint s'apparente à une figure publique ou politique, ni, à plus forte raison, que ses vertus revêtent une signification profane. L'exemple le plus parlant à cet égard est sans doute la Vie de Bernard d'Abbeville, abbé de Tiron, écrite entre 1137 et 1149 par son élève Geoffroi le Gros ${ }^{71}$. Le long passage sur les vertus cardinales observées par le saint est dans son intégralité une compilation de phrases reprises de Macrobe: les définitions des vertus et de leurs sous-espèces que l'auteur néo-platonicien propose dans son commentaire sont fidèlement reproduites, les adaptations demeurant très légères. Apparemment, Geoffroi n'avait aucune difficulté à calquer sa taxonomie des vertus du saint sur cet ouvrage de philosophie païenne, même s'il souligne que c'est le Saint-Esprit qui assura les vertus de Ber$\operatorname{nard}^{72}$. Tout porte à croire que le conflit entre éthique ancienne et morale chrétienne, très palpable chez les Pères de l'Église, n'existait plus pour les hagiographes du Moyen Âge central. Plutôt que d'avoir harmonieusement fondu vertus anciennes et chrétiennes, les auteurs ont librement puisé dans les deux catégories; même les emprunts directs à la philosophie païenne

erat superbus et uanus, referendum est ad exteriorem apparentiam, non ad rei existentiam; non enim in rei ueritate uanus et superbus erat, sed talis esse apparebat propter quedam uerba iocosa que uidebatur esse uanitatis et superbie signa.

${ }^{69}$ Cf. Sénèque, Epistulae morales ad Lucilium, 120.11, ed. Fr. PRÉcHAC (= Collection des Universités de France), t. V, Paris, 1964, p. 69: oportebat cupiditates refrenari, metus comprimi, facienda provideri, reddenda distribui: conprehendimus temperantiam, fortitudinem, prudentiam, iustitiam et suum cuique dedimus officium; Cicéron, De finibus, 2.19.60, ed. Th. SCHICHE (= Bibliotheca Scriptorum Graecorum et Romanorum Teubneriana), Leipzig, 1915, p. 60: la tempérance est moderatio cupiditatum rationi oboediens.

$70 *$ Florentius, c. 2.18 [p. 435E-F].

${ }^{71}$ Voir J. DE BASCHER, La «Vita» de saint Bernard d'Abbeville, abbé de Saint-Cyprien de Poitiers et de Tiron, in Revue Mabillon, 59 (1976-1980), p. 411-450.

72 *Bernardus Tironiensis: Spiritus sancti gratia omnium contulerat incrementa virtutum. Macrobe, Commentarii, 1.8.7, sert de référence principale à Geoffroi, qui reprend également des extraits de 1.8.4 et 1.8.8-9. Un passage seulement, à propos de la tempérance, n'est pas emprunté à Macrobe: [rationi] omnia postponere. 
n'empêchent nullement une conception profondément religieuse des vertus. Attitude assez différente de celle des philosophes et théologiens qui, à partir du XII ${ }^{\mathrm{e}}$ siècle, ont commencé à repenser le rapport entre les vertus cardinales et la religion ${ }^{73}$, écartant ainsi l'assomption des générations antérieures que le caractère chrétien de toutes les vertus allait de soi. Comparativement, le traitement des vertus cardinales par les hagiographes se caractérise par une heureuse insouciance.

\section{La diffusion de la tradition au bas Moyen Âge}

La tradition hagiographique dont nous nous occupons a évolué de façon surprenante dans les trois derniers siècles du Moyen Âge. Tout d'abord, on ne peut manquer d'être frappé par les données quantitatives. Loin de prolonger la tendance à la hausse des siècles antérieurs, le bas Moyen Âge affiche une forte décroissance des sources hagiographiques évoquant les vertus cardinales. Pour le XIII ${ }^{\mathrm{e}}$ siècle, notre dossier compte seulement neuf textes, ce qui réduit notre tradition aux dimensions qu'elle possédait à l'époque carolingienne. Durant le siècle suivant, elle tombe même plus bas, ayant laissé à peine quatre témoignages. $\mathrm{Au} \mathrm{XV}^{\mathrm{e}}$, elle reprend de l'ampleur mais, avec dix-huit textes, nous restons toujours loin en-dessous des chiffres du Moyen Âge central ${ }^{74}$. Outre ces tendances, on constate un déplacement géographique très net: au $\mathrm{XV}^{\mathrm{e}}$ siècle, ce sont les Vies italiennes qui dominent ${ }^{75}$. Les vertus cardinales ont donc connu aux

${ }^{73}$ Voir I. P. BEJCZY, The Problem of Natural Virtue, in Virtue and Ethics in the Twelfth Century, ed. I. P. BEJCZY - R. G. NEWHAUSER, Leyde (à paraître).

${ }^{74}$ XIII ${ }^{\text {e: }}$ *Edmundus $[1,2,3]$, *Elisabeth, *Notkerus, *Paulus, *Petrus Monoculus, *Richardus Cicestrensis, *Willelmus Magnus. XIV ${ }^{\mathrm{e}}{ }^{*}$ Clara, *Petrus de Luxemburgo, *Petrus de Murrone (le passage sur les vertus porte cependant sur Matteo Rosso Orsini, mort en 1305), *Waldburgis. Xve: *Anianus, *Antoninus, *Bernardinus, *Bonaventura, *Catharina Senensis [1, 2 (l'hagiographe recommande les vertus sans les associer explicitement à la sainte), 3], *Francisca, *Hildegardis, *Iohannes Bassandus (il manque la justice), *Iohannes de Capistrano $[1,2]$, *Ivo, *Meinulfus, *Rainaldus, *Thomas Aquinas (il manque la tempérance), *Thomas Florentinus (il manque le courage), *Ursulina. Nous n'avons pu dater *Crescentius; d'après F. CARAFFA, Crescenzio di Firenze, in Bibliotheca sanctorum, t. 4, Rome, 1964, p. 291, cette Vie est «molto più recente» que celles de $\mathrm{S}$. Zénobe $(B H L 9015,9017,9018)$ qui le mentionnent également. Voir aussi la Vie anonyme de Quinide de Vaison (BHL 6996), c. 2.7, ed. AASS, Febr. t. 2 , p. $831 \mathrm{~A}$, où la prudence et la tempérance du saint sont mentionnées dans ce qui s'annonce comme une liste de ses vertus (comme le texte présente une lacune, on ignore si l'hagiographe a évoqué les deux autres vertus cardinales).

${ }^{75}$ Entre 500 et 1200 , on dénombre neuf Vies italiennes sur un total de quatre-vingt-onze récits (*Apianus, *Berardus, *Bononius, *Decorosus, *Lucius, *Paternianus, *Petrus Trebanus, $*$ Restituta, *Walfardus), soit $10 \%$. Entre 1200 et 1500 , on en compte dix-sept sur un total de trente-deux (*Antoninus, *Bernardinus, *Bonaventura, *Catharina Senensis $[1,2,3],{ }^{*}$ Clara, *Crescentius, *Francisca, *Iohannes de Capistrano [1, 2], *Paulus, *Petrus de Murrone, *Rai- 
$\mathrm{XI}^{\mathrm{e}}$ et $\mathrm{XII}^{\mathrm{e}}$ siècles l'apogée de leur popularité dans l'hagiographie médiévale; elles tombèrent ensuite en désuétude, jusqu'à leur redécouverte au Quattrocento.

De prime abord, nos statistiques défient la compréhension. À partir du XIII ${ }^{\mathrm{e}}$ siècle, on peut en effet constater une croissance explosive de l'attention pour les vertus cardinales dans les genres pastoraux et didactiques: traités de vertus et de vices, sermons, encyclopédies, ouvrages de moralité comme les miroirs de princes, etc. ${ }^{76}$ En outre, il y a la production académique: les théologiens traitent des quatre vertus dans leurs sommes et dans leurs commentaires sur les Sentences de Pierre Lombard ${ }^{77}$; les philosophes font de même dans leurs innombrables questions inspirées de l'Éthique d'Aristote, entièrement disponible en latin vers 1250 et intégrée dans le curriculum régulier des universités, à Paris et ailleurs, dans le courant du XIV $\mathrm{XI}^{\mathrm{e}}$ siècle. Tous les grands scolastiques et la plupart des moralistes de renommée plus modeste discutent des quatre vertus - mais de cette activité fourmillante, l'hagiographie latine de l'époque ne retient guère que des reflets. Au bas Moyen Âge, on trouve plus aisément des saints qui ont écrit sur les vertus cardinales que des saints qui, d'après leurs biographes, ont respecté ces vertus dans leur vie personnelle... La Vie d'Antonin de Florence en offre un exemple typique: son biographe note que le cardinal florentin disserta sur les quatre vertus dans sa Summa, mais il ne fait aucun effort pour intégrer ces vertus dans son récit sur la conduite du saint ${ }^{78}$.

Malgré ces constatations, nous n'avons pas l'impression que les hagiographes du bas Moyen Âge aient perdu leur intérêt pour les vertus cardinales considérées en elles-mêmes. On peut facilement relever des Vies latines, y compris des productions du XIV ${ }^{\mathbf{e}}$ siècle, qui citent seulement une ou deux vertus cardinales; la tempérance notamment est souvent

naldus, *Thomas Aquinas, *Thomas Florentinus, *Ursulina), soit plus de 50\%; treize de ces textes, sur un total de dix-sept, furent composés au $X v^{\mathrm{e}}$ siècle.

${ }^{76}$ Voir M. W. BLoOMFIELD et al., Incipits of Latin Works on the Virtues and Vices, 1100 1500 A.D. (= Mediaeval Academy of America. Publications, 88). Cambridge, 1979, ouvrage à compléter par celui de R. G. NEWHAUSER - I. P. BEJCZY, Towards a Revised Incipitarium: A Preliminary List of Additions, Corrections, and Deletions to Update Morton Bloomfield et al., Incipits of Latin Works on the Virtues and Vices (à paraître); voir aussi NEWHAUSER, The Treatise... (cf. supra, n. 21), p. 127-129.

${ }^{77}$ Voir Pierre Lombard, Sententiae, III.33 (= Spicilegium Bonaventurianum, 5), Grottaferrata, 1981, p. 187-189. Pour un survol de la conception de la justice dans les commentaires sur ce passage aux XII ${ }^{\mathrm{e}}$ et XIII ${ }^{\mathrm{e}}$ siècles, voir LIO, Il testo di $S$. Agostino... (cf. supra, n. 56).

${ }^{78}$ L'ouvrage d'Antonin fut édité sous le titre Summa theologica, 4 t., Vérone, 1740 (rééd. Graz, 1959). Conformément aux dires de son hagiographe, la quatrième partie traite des vertus. 
mentionnée sans que les trois autres vertus entrent en jeu (fait assez exceptionnel dans la littérature médiévale, la tempérance n'apparaissant normalement qu'en compagnie de ses trois sœurs) ${ }^{79}$. Aussi Prosper Lambertini pouvait-il citer dans son ouvrage sur les canonisations maintes Vies du bas Moyen Âge se focalisant sur une vertu cardinale en particulier. De plus, l'habitude d'associer les vertus cardinales aux saints subsiste en dehors de l'hagiographie latine, comme en témoigne l'œuvre de Jean Gerson: à deux reprises, le chancelier parisien parle dans ses œuvres latines des vertus cardinales de Jean-Baptiste, tandis qu'il les attribue à Antoine dans un sermon français sur ce saint ${ }^{80}$. Ce que les hagiographes latins de l'époque ont évité, ce n'est pas l'utilisation des vertus cardinales individuelles; ils avaient plutôt tendance à écarter le schéma des quatre vertus, contrairement à la mode qui régnait dans la littérature, la théologie et la philosophie contemporaines. Quelle peut en être la cause? Plutôt que d'expliquer l'écart de notre schéma par une baisse générale de la popularité des quatre vertus - cette baisse n'existait pas, les vertus cardinales étant plus populaires que jamais - il faut se tourner vers les circonstances propres à la vénération même des saints.

C'est pendant le premiers tiers du XIII ${ }^{\mathrm{e}}$ siècle - à l'époque où les citations des vertus dans nos sources commencent à devenir nettement plus rares - que la réserve papale de la canonisation s'est définitivement établie ${ }^{81}$. Obligés dès lors de définir les critères pour l'examen des candidatures, les papes et les canonistes ont insisté sur l'importance des vertus dans la vie des saints, comme l'a remarqué André Vauchez, alors que la vénération populaire reposait surtout sur les miracles accomplis par ceux-

${ }^{79}$ Deux vertus: Vie de Procope (milieu du XIV ${ }^{\mathrm{e}}$ s.; voir n. 35 ci-dessus); Raymond de Capoue, Vie de Catherine de Sienne (vers 1395; BHL 1702), c. 2.138, ed. AASS, Apr. t. 3, p. 888B: Hinc postea procedit virtutum cunctarum augmentum, patientiae scilicet, fortitudinis, temperantiae, solicitudinis et diligentiae in operibus sanctitatis, fidei, spei, et caritatis, et universorum virtuosorum habituum indeficiens incrementum. Tempérance seulement: Hugues de Floreffe, Vie d'Yvette d'Huy (vers 1230; BHL 4620), c. 18.50-52, ed. AASS, Ian. t. 1, p. 873; Vie anonyme de Thiadildis de Freckenhorst ( $\mathrm{xv}^{\mathrm{e}} \mathrm{s}$; $B H L 8131$ ), c. 3.13, ed. AASS, Ian. t. 2, p. 1158: temperantia, quae inter quatuor virtutes est optima. M. DE REU, Vertus chrétiennes et vices démoniaques aux $X^{e}$ et $X I^{e}$ siècles, in Predicazione e società nel Medioevo: riflessione etica, valori e modelli di comportamento. Atti del XII Medieval Sermon Studies Symposium, ed. L. Gaffuri - R. Quinto (= Centro Studi Antoniani, 35), Padoue, 2002, p. 110-111, montre qu'aux $\mathrm{X}^{\mathrm{e}}$ et $\mathrm{XI}^{\mathrm{e}}$ siècles la tempérance était beaucoup plus rarement mentionnée que les autres vertus cardinales et théologales.

${ }^{80}$ Jean Gerson, De comparatione vitae contemplativae ad activam, in Cuvres complètes, ed. P. GlorieuX, t. 3, Paris, 1962, p. 67 (Jean-Baptiste); In Marc. 1, 7, ibid., p. 103 (JeanBaptiste; la tempérance est omise); En la fête de S. Antoine, ibid., t. 7, Paris, 1966, p. 561-572. Je remercie Céline Billot-Vilandrau pour ces références.

${ }^{81}$ VAUCHEZ, La sainteté en Occident... (cf. supra, n. 5), p. 34-35. 
ci pendant et après leur vie. Mais les exigences officielles de la vertu se concentraient sur la foi, la simplicité, l'humilité et la chasteté, non pas sur notre schéma. Durant le procès de Claire de Montefalco (Clara de Cruce), au début $\mathrm{du} \mathrm{XIV}^{\mathrm{e}}$ siècle, son propre frère avait beau interpréter le comportement de la sainte à la lumière des vertus théologales et cardinales, «on ne les retrouve pas [de tels concepts théologiques précis] dans les articles ou les documents rédigés à la Curie, qui restent fidèles à des modèles directement inspirés par la littérature hagiographique la plus traditionnelle ${ }^{82}$. Notons que 1'on peut qualifier de tout aussi traditionnelle l'attitude du frère de Claire, vu que l'habitude d'associer les saints aux vertus existait depuis un millénaire; la Curie aurait pu agréer sa démarche sans crainte de paraître déroger à la tradition.

Il serait logique de supposer qu'en règle générale, les hagiographes du bas Moyen Âge, souvent actifs avant ou pendant les procès de canonisation, se sont épargné la peine d'évoquer les qualités de leurs héros qui ne pouvaient que peu contribuer à leur réputation de sainteté. S'adaptant aux nouvelles circonstances au cours du XIII ${ }^{\mathrm{e}}$ siècle, ils ont sans doute d'abord souligné les caractéristiques qui se conformaient aux critères officiels de la sainteté définis et appliqués par le Saint-Siège. Cette explication reste hypothétique, bien entendu, mais nous croyons qu'elle n'est pas dénuée de sens. L'hagiographie repose sur les exigences de son temps, et l'indifférence papale face aux vertus cardinales - dont la mention dans l'hagiographie était toujours demeurée facultative, comme nous l'avons vu, même au Moyen Âge central — a forcément contribué à leur disparition graduelle dans les Vies de saints. La conception de la sainteté étant devenue une réalité politique, les hagiographes auraient manqué leur but en refusant de s'y soumettre. Mieux valait la fabrication de portraits «politiquement corrects» des saints, en anticipant les attentes de la Curie. Si les Vies des $\mathrm{XVII}^{\mathrm{e}}, \mathrm{XVIII}^{\mathrm{e}}$ et $\mathrm{XIX}^{\mathrm{e}}$ siècles suivent généralement le schéma des sept vertus, devenu critère de sainteté sous l'influence des papes, un

${ }^{82}$ VAUCHEZ, La sainteté en Occident... (cf. supra, n. 5), p. 606. La constatation de Vauchez contredit l'affirmation de R. HofmanN, Die heroische Tugend. Geschichte und Inhalt eines theologischen Begriffes (= Münchener Studien zur historischen Theologie, 12), Munich, 1933, p. 152-153: «In der Frage nach der Heiligkeit der Lebensfuihrung tritt jetzt [au début du $\mathrm{XIV}^{\mathrm{e}}$ siècle] neben die allgemeine Darstellung des Lebens eine besondere systematische Erörterung der einzelnen Tugenden nach der Disposition der drei theologischen und der vier Kardinaltugenden, also neben das Urteil de vita et virtutibus in genere ein solches de virtutibus in specie. Aus der früheren Zweiteilung vita et miracula wird jetzt die Dreiteilung vita - virtutes - miracula. Diese Dreiteilung entwickelte sich seit dem 14. Jahrhundert und wird im Laufe des 16. Jahrhunderts allgemein üblich»». 
développement inverse semble très probable au bas Moyen Âge, corrélativement à la politique papale.

Il est intéressant de relever dans ce contexte le rôle des deux grands Ordres mendiants. Contrairement aux Bénédictins et surtout aux Cisterciens - Bernard de Clairvaux avait souvent discuté des vertus cardinales dans ses œuvres, y compris dans deux écrits à caractère hagiographique (*Malachias, *Victor); le schéma apparaît dans sa propre biographie et s'est maintenu ensuite dans l'hagiographie cistercienne ${ }^{83}$ - les mendiants du Moyen Âge semblent avoir porté peu d'intérêt aux quatre vertus dans leurs Vies de saints (ou dans les Vies de leurs saints). L'apport des Dominicains demeure très modeste jusqu'à la fin de notre période, en dépit de l'autorité de plusieurs illustres frères prêcheurs dans les domaines de la philosophie et la théologie morales. On a déjà cité la Vie du dominicain Antonin de Florence, où l'auteur, un chanoine régulier, évoque les vertus cardinales parmi les sujets débattus par ce savant archevêque et non pas parmi ses qualités. Même les biographies de Thomas d'Aquin passent habituellement notre quatuor sous silence, tandis que c'est au docteur angélique que les papes et hagiographes modernes devaient emprunter leur conception des sept vertus. Une seule Vie tardive attribue les vertus cardinales au docteur angélique, sans que l'auteur ait été lui-même frère prêcheur $^{84}$; inversement, deux hagiographes dominicains, Ralph Bocking et Maurice Gaufridus, ont associé les vertus à des saints qui n'appartenaient pas à leur ordre (*Ivo, *Richardus Cicestrensis). C'est surtout à Catherine de Sienne que plusieurs hagiographes rattachèrent le schéma. Sa biographie principale par Raymond de Capoue n'évoque que le courage et la tempérance, tandis que le Libellus de supplemento de Thomas Caffarini ignore totalement notre thème ${ }^{85}$. Par contre, Bartholomé de Ferrare,

\footnotetext{
${ }^{83}$ Voir *Bernardus Claravallensis, *Mathildis; *Elisabeth, *Petrus Monoculus (XIII ${ }^{\mathrm{e}} \mathrm{s}$ )); *Waldburgis (XIV s.). Tous ces textes ont été écrits par des Cisterciens.

${ }^{84}$ L'hagiographe, Antonio Pizzamano, fait le lien entre les activités intellectuelles de Thomas et sa prudence (quali autem fuerit prudentia eius indicant opuscula. Nam a regibus principibusque dubiis in rebus consulebatur) ainsi que sa justice (verbis aut scriptis ipsam mortales docuit omnes). Il nous semble qu'Antonio a également inséré les vertus cardinales dans quatre passages qui décrivent le physique et le caractère du saint: sa peau était colore sub albo temperate; fortissimus fuit animi atque corporis robore; dans toutes les difficultés iudicio vsus est; enfin, il possédait un ingenium extraordinaire. En plus de cette Vie (BHL 8160), nous avons consulté $B H L 8150$ à $8153,8155,8156,8158,8161,8163$ à $8167,8149 \mathrm{t}, 8151 \mathrm{~d}, 8151 \mathrm{~g}$, $8151 \mathrm{k}, 8151 \mathrm{~m}, 8156 \mathrm{a}, 8158 \mathrm{a}, 8158 \mathrm{~d}, 8160 \mathrm{~d}, 8163 \mathrm{f}$, le récit dans l'Historia plurimorum sanctorum, Louvain, 1485 , f. $39^{\mathrm{va}}-40^{\mathrm{vb}}$, et le c. 23.7 , dédié à Thomas dans Antonin Pierozzi (Antoninus ep. Florentinus), Chronicorum opus, t. 3, Lyon, 1586, p. 644-656.

${ }^{85}$ Pour la Vie composée par Raymond, voir la citation dans n. 79 ci-dessus; pour l'ouvrage de Caffarini voir $B H L 1704 \mathrm{~b}$.
} 
confrère de Catherine, érigea la sainte en exemple des vertus cardinales dans un sermon prononcé à Venise en 1411, qui devait entraîner l'ouverture du procès informatif diocésain au sujet de Catherine dans les années à suivre (ironiquement, Bartholomé invoqua pendant ce procès l'œuvre de Raymond pour corroborer son opinion) ${ }^{86}$. C'est peut-être sous l'influence de ce sermon que notre schéma rentra dans la Legenda abbreviata de Caffarini ainsi que dans une Vie concise et anonyme de la sainte dominicaine, ajoutée au $\mathrm{XV}^{\mathrm{e}}$ siècle à la Légende dorée de Jacques de Voragine ${ }^{87}$.

Quant aux Franciscains, ils passèrent d'abord les vertus sous silence. Le XIII ${ }^{\mathrm{e}}$ siècle nous a légué un sermon qui associe Élisabeth de Hongrie, devenue tertiaire à la fin de sa vie, aux quatre vertus, mais son auteur est le cistercien Césaire d'Heisterbach; pour le siècle suivant, on ne peut citer que le témoignage mal reçu du frère de Claire de Montefalco ${ }^{88}$, lui-même frère mineur, tandis que sa sœur avait suivi la règle d'Augustin ${ }^{89}$. De fait, les vertus cardinales ne figurent ni dans les propres ouvrages de François d'Assise ni dans les légendes composées sur le saint aux XIII et XIV ${ }^{\mathrm{e}}$ siècles, qui s'étendent au contraire longuement sur sa charité, son humilité et sa mansuétude ${ }^{90}$. On doit à Jacques de Voragine un sermon sur François

86 *Catharina Senensis [1] [col. 1250]: dixi \& dico, quod notitiam supradictarum virtutum eximiarum ac mirabilis doctrinae dictae virginis habui ex publica ejus fama, ac etiam ex devota et ordinata legenda ejusdem, quam composuit quidam magister Raymundus de Vineis de Capua. Le texte du sermon est conservé dans les actes du procès.

${ }^{87}$ La Legenda abbreviata (BHL 1704c) est connue dans une deuxième rédaction (BHL $1704 d / e, c f .1704)$; cette deuxième rédaction fut adaptée par Antoine della Rocca (BHL 1705b) qui supprima le passage sur les vertus; voir A. SABA, La leggenda abbreviata di S. Caterina da Siena scritta da Fr. Antonio della Rocca, in Aevum, 8 (1934), p. 305. Voir aussi n. 104 cidessous. En plus des sources mentionnées, nous avons consulté $B H L 1703,1704 \mathrm{f}, 1704 \mathrm{~g}$, 1705c (extraits publiés par Franceschini), 1706, 1706b et 1709.

${ }^{88}$ Dans la biographie proprement dite de la sainte, écrite par Bérenger de Saint-Africain (BHL 1818), ed. A. SEMENZA, Vita S. Clarae de Cruce ex codice Montefalconensi saeculi XIV desumpta, in Analecta Augustiniana, 17 (1939/1940), p. 87-102, 169-76, 287-99, 337-49, 393$409,445-57,513-17$, les vertus cardinales font défaut.

${ }^{89} \mathrm{La}$ communauté que Claire rejoignit accepta la règle d'Augustin en 1290, mais subit également des influences franciscaines. Claire en devint la deuxième abbesse.

${ }^{90}$ Sur ces légendes, voir Legendae S. Francisci Assisiensis (= Analecta Franciscana, 10), Quaracchi, 1926-1941, et Testimonia minora saeculi XIII de S. Francisco Assisiensi, ed. L. LEMMENS (= Collectanea philosophico-theologica, 3), Quaracchi, 1926. Seul Henri d'Avranches, Legenda versificata (1232/1234; BHL 3101), 1. 2, v. 117-143, ed. Legendae S. Francisci..., p. 418-419, se rapproche d'un schéma précis en énumérant les vertus de François: le saint possédait les trois vertus théologales et les sept vertus-remèdes qui s'opposent aux sept péchés capitaux. Quant aux propres travaux de François, on peut signaler une exception possible: Chartula fratri Leoni data, ed. K. EsSER, Die Opuscula des Hl. Franziskus von Assisi (= Spicilegium Bonaventurianum, 13) Grottaferrara, 1976, p. 142: appelant Dieu par de nombreux noms qui reflètent les qualités divines, François semble citer les quatre vertus (mais pas en série, et en remplaçant prudentia par sapientia). 
sous le titre prometteur De quatuor virtutibus in eo repertis, mais il s'agit ici d'un exposé sur la paupertas, l'humilitas, l'amor et l'obedientia respectées par le saint ${ }^{91}$.

$\mathrm{Au} \mathrm{XV}^{\mathrm{e}}$ siècle, la situation évolua. Parmi les dix-huit sources de notre recueil que l'on peut situer dans ce siècle, on en compte six, toutes d'origine italienne, qui sont liées aux Frères mineurs. Cinq Vies ont pour héros un saint appartenant à l'Ordre (et trois d'entre elles furent écrites par un confrère); la sixième, un récit sur l'archevêque Raynaud de Ravenne, émane d'une plume franciscaine ${ }^{92}$. L'intérêt tardif pour les vertus cardinales des Franciscains italiens a donc sensiblement concouru à la renaissance de notre schéma dans l'hagiographie du $X V^{e}$ siècle. Notons cependant que le schéma ne constituait nullement un ingrédient fixe dans la production hagiographique de l'Ordre. Barnabé de Sienne, le premier biographe de son concitoyen Bernardin, a amplement digressé sur la manifestation des quatre vertus dans la vie du saint, mais aucun de ses nombreux successeurs au XV ${ }^{\mathrm{e}}$ siècle n'a marché dans ses traces; dans les actes du procès de canonisation de Bernardin, les quatre vertus n'ont pas laissé d'empreinte non plus ${ }^{93}$.

Comme nous l'avons déjà dit, les vertus cardinales apparurent pour la première fois dans le procès de canonisation d'un saint franciscain, Bonaventure, en 1482. Jean François Pavini, juriste de Padoue et auditeur de la Rote, inséra un récit sur les vertus du saint dans sa relatio adressée au pape Sixte IV, sans d'ailleurs suivre strictement le schéma des vertus théologales et cardinales: parlant également d'autres vertus, son exposé sur les vertus cardinales se concentre sur la prudence et la tempérance (représentée par une de ses sous-espèces, l'humilité); le chapitre sur le regimen iconomicum et politicum de Bonaventure rappelle bien la justice, mais cette vertu n'est pas appelée par son nom, tandis que le chapitre suivant sur la patience qualifie cette dernière de pars fortitudinis. De plus, ce chapitre évoque, rapidement il est vrai, le schéma des sept vertus. Mais

${ }^{91}$ Testimonia minora saeculi XIII de S. Francisco... (cf. note précédente), p. 117-121 (absent de la $B H L$ ).

${ }^{92}$ Les cinq autres Vies sont *Bernardinus, *Bonaventura, *Iohannes de Capistrano $[1,2]$, *Thomas Florentinus. Les trois dernières furent écrites par des Franciscains.

${ }^{93}$ Nous avons consulté $B H L 1189$ à 1200,1187m, 1188b, 1188g, 1190b, 1190c, 1192b, $1196 \mathrm{~b}$ (dans l'édition partielle de F.-M. Delorme), 1200b. Pour les actes du procès de 1448 (BHL 1187n), voir C. PIANA, I processi di canonizzazione su la vita di S. Bernardino da Siena, in Archivum franciscanum historicum, 44 (1951), p. 87-160 et 383-435. Ces actes ne mentionnent que la prudence du saint (art. 28, p. 426) tout en louant nombre de ses autres vertus, telles l'humilité et la patience (art. 29, p. 426-430), la charité (art. 30, p. 430-432) et la chasteté (art. 31, p. 432-433). 
nos quatre vertus sont présentes; et Pavini de parsemer son récit de nombreuses citations - de Thomas d'Aquin surtout, mais également de la Bible, du droit canonique, d'Augustin, de Grégoire le Grand, de Gilles Romain, d'Anselme et même d'Aristote - en vue de prouver l'importance des vertus pour la foi en général et la sainteté en particulier ${ }^{94}$. Pourtant, malgré ses efforts, on ne retrouve les vertus cardinales ni dans la bulle de canonisation publiée par Sixte IV, ni dans les autres textes hagiographiques consacrés à Bonaventure ${ }^{95}$. Qui plus est, deux ans plus tard, en 1484, Pavini rédigea à nouveau un rapport final dans le procès d'un saint, Léopold d'Autriche. Cette fois-ci, les quatre vertus ne figurent pas dans son discours (sinon de façon très cachée); de plus, elles sont absentes de la biographie du saint que Pavini composa personnellement... ${ }^{96}$ Tout porte à croire que l'apparition de notre schéma dans le procès de Bonaventure constituait un cas isolé. Pour les fonctionnaires de la Curie, les critères de sainteté n'avaient pas encore changé. La redécouverte modeste des vertus cardinales dans l'hagiographie du $\mathrm{XV}^{\mathrm{e}}$ siècle ne s'explique donc pas par une nouvelle politique du Saint-Siège. Il semble, au contraire, que la ré-

${ }^{94}$ Sur Pavini, voir A. Bertola, François de Pavinis, in Dictionnaire de droit canonique, t. 5, Paris, 1952, col. 899-901. Prudence, tempérance et autres vertus: *Bonaventura, c. 1.4 [f. $9^{\mathrm{va}}-11^{\mathrm{vb}}$; le c. 1.5 parle du regimen iconomicum et politicum, le c. 1.6 de la patience (pars fortitudinis [f. $12^{\mathrm{va}}$ ]). Référence aux sept vertus: [patientia] deficit a virtutibus theologicis et cardinalibus que retrahunt a maioribus impedimentis (ibid.), paraphrasant Thomas d'Aquin, Summa theologiae, II.II.136.2 (cf. supra, n. 49), p. 99: [patientia] deficit non solum a virtutibus theologicis et prudentia et iustitia, quae directe statuunt hominem in bono; sed etiam a fortitudine et temperantia, quae retrahunt a maioribus impedimentis.

${ }^{95}$ Nous avons consulté les sources répertoriées dans la $B H L\left(\mathrm{n}^{\text {os }} 1390 \mathrm{~d}, 1391,1391 \mathrm{a}\right.$, $1391 \mathrm{~m}, 1391 \mathrm{n}$ et l'appendice de la Legenda aurea) ainsi que la bulle de canonisation de Sixte IV, imprimée dans Bonaventure, Opuscula, Strasbourg, 1495, f. $23^{\mathrm{ra}}-24^{\mathrm{vb}}$.

${ }^{96}$ Summarium canonizationis sancti Leopoldi... (BHL 4890), ed. H. PEZ, Scriptores rerum austriacarum veteres ac genuini, t. 1, Leipzig, 1721, col. 592-672. Si le chapitre 6 (col. 618621) discute les vertus de Léopold sans mentionner notre schéma, on lit cependant le passage suivant (col. 618): Sic etiam dicendum dico de Pio Leopoldo nostro ... in pietate, justitia, multa patientia, longanimitate, pudicitia, castitate, humilitate, sobrietate, prudentia, mansuetudine, caritate, liberalitate, reliquisque omnibus virtutibus magnam super excellentiam habuisse... Si on assimile patientia et longanimitas à courage, et pudicitia / castitas / humilitas / sobrietas à tempérance (ce qui n'a rien d'inhabituel), on peut concéder que le catalogue fut partiellement inspiré par notre schéma, mais on reste loin d'un examen de la sainteté effectué à la lumière des quatre vertus. Dans deux autres passages du même ouvrage, le rapport avec notre schéma apparaît encore plus ténu: Siquidem ejus pietas, justitia, prudentia, castimonia, humilitas, pudicitia, mansuetudo, et multiplex in eo mirabilis gratia divinitus sibi collata consideretur (c. 6, col. 620); ... modestum, prudentem, humilem, generosum, Religiosorum et pauperum patrem, benignum, sobrium, pudicum atque castum... (c. 1, col. 594). Sur la Vie de Léopold par Pavini (BHL 4889), voir PEZ, Summarium canonizationis..., p. 577-593; les vertus sont également absentes des textes sur Léopold édités par R. RUDOLF, Die liturgische Gestalt der drei ältesten Leopold-Offizien, in Archiv für Liturgiewissenschaft, 5 (1957), p. 1-32 (cf. BHL 4891). 
introduction de ces vertus dans les Vies de saints a préparé le chemin pour leur apparition, très incertaine encore vers 1500 , dans les procès de canonisation.

\section{Les caractéristiques de la tradition au bas Moyen Âge}

Hormis la grande fluctuation dans le nombre des références, le fonctionnement des vertus cardinales dans l'hagiographie latine au bas Moyen Âge ne semble pas avoir subi d'importantes modifications. La brièveté reste la règle: la plupart des références évoquent sommairement les vertus, en les liant parfois à d'autres concepts; on rencontre parfois, avec la même fréquence qu'aux siècles antérieurs (dans un cas sur sept environ), le schéma des trois vertus théologales et des quatre vertus cardinales ${ }^{97}$. L'importance relative des saintes dans notre recueil s'accrôt assez clairement vers la fin du Moyen Âge. Une des neuf sources datant du XIII ${ }^{e}$ siècle se rapporte à une femme (*Elisabeth); pour le XIV ${ }^{\mathbf{e}}$, nous disposons de deux Vies de saintes ( ${ }^{*}$ Clara, ${ }^{*}$ Waldburgis) contre le même nombre de textes dédiés à des saints masculins; pour le $\mathrm{XV}^{\mathrm{e}}$, on compte, sur un total de dix-huit textes, six récits sur des saintes $\left({ }^{*}\right.$ Catharina Senensis $[1,2,3]$, *Francisca, *Hildegardis, *Ursulina). Les hagiographes des $\mathrm{XIV}^{\mathrm{e}}$ et $\mathrm{XV}^{\mathrm{e}}$ siècles souffraient apparemment de moins de préjugés que les artistes de l'époque, hésitant, pour leur part, à associer les quatre vertus aux femmes, exception faite de celles qui avaient personnellement exercé le pouvoir public $^{98}$.

Le plus long exposé sur les vertus cardinales qui figure dans les sources hagiographiques du bas Moyen Âge est néanmoins intimement lié au rôle public occupé par un saint. D'après son premier biographe, Bernardin de Sienne excellait dans les quatre vertus. Sa justice se manifestait d'abord dans sa révérence pour Dieu et tous les saints, puis dans sa piété et sa charité erga patriam (allusion limpide à la définition cicéronienne de la piété en tant que sous-espèce du droit naturel ${ }^{99}$ ). Seul le côté politique de la justice de Bernardin se trouve ensuite développé. La patrie faisait l'objet du désir et de l'espoir du saint, souligne l'hagiographe (il s'agit bel et bien de sa patrie terrestre, la ville de Sienne!); c'est là qu'il habitait

\footnotetext{
${ }^{97}$ Voir *Edmundus [2], *Francisca, *Ivo, *Ursulina, *Waldburgis; cf. Raymond de Capoue, Vie de Catherine de Sienne, citée $n .79$ ci-dessus.

${ }^{98}$ Ainsi M. BAUTz, Virtutes. Studien zu Funktion und Ikonographie der Tugenden im Mittelalter und im 16. Jahrhundert, Berlin, 1999, p. 61-65.

${ }^{99}$ Cicéron, De inventione, 2.22.66, ed. E. STRÖBEL (cf. supra, n. 10), p. 105: pietatem, quae erga patriam aut parentes aut alios sanguine coniunctos officium conservare moneat.
} 
dans son monastère et qu'il se rendait aussi utile pour la cause commune dans la solitude, en écrivain moral, que par ses admonitions quotidiennes en public. Son plus grand mérite est d'avoir réussi à apaiser, grâce à ses allocutions privées et ses interventions dans les réunions politiques, la discorde qui régnait dans sa ville. Il transforma les citadins en une communauté unie et harmonieuse, prête à agir dans l'intérêt public et capable de préserver la ville de ses ennemis:

Itaque et seditiosas in Republica partes suis admonitionibus compressit; et cives varie de republica sentientes, unanimes concordesque fecit; inimicitias et odia, in animis civium inveterata, in pacem benevolentiamque convertit; et usque adeo familiari ejus sermone animos hominum quos quotidie conveniret persuasit, ut una omnium civium mens atque idem animus videretur. Itaque semel cum in frequentem Senatum venisset, cives quos antea solos convenisset, eo die universos peracri quadam oratione allocutus est; idemque omnibus faciendum dixit, quod jam unicuique privatim persuaserat. Itaque ejus civitatis status in perpetuum confirmatus solidatusque est, si cives in futurum (quod Deus omen avertat) non inter se pugnare, sed ab hostibus rempublicam pari studio ac laboribus vendicare velint ${ }^{100}$.

La ressemblance avec quelques Vies antérieures qui mettent en relief le rôle public du saint (*Adalhardus, *Berardus, *Odilo) est incontestable. À nouveau, la justice vient en tête des vertus qui illustrent les accomplissements politiques du saint plutôt que ses qualités sur le plan spirituel, tandis que la prudence est interprétée comme l'intelligence dans les affaires d'État: dans le cas de Bernardin, tous les Italiens profitaient de ses sages conseils mais surtout les princes qui cherchaient son amitié et lui demandaient sans cesse son avis, suite à quoi ils pouvaient établir la paix dans leurs villes et pays ${ }^{101}$. Il nous semble toutefois que le rôle public du saint a quelque peu changé par rapport au haut Moyen Âge. Ce n'est pas contre les brigands qui infestent le pays et oppriment les humbles que Bernardin se dresse au nom d'un souverain qui lui a délégué le pouvoir; son œuvre majeure est d'imposer, de sa propre initiative, l'esprit public partout où il fait défaut, et en premier lieu dans sa patrie à laquelle il est profondément attaché. Nous croyons que Barnabé de Sienne a voulu présenter son illustre concitoyen à la lumière de ce que les historiens de la Renaissance appellent l'humanisme civique, et qu'il s'est servi dans ce

$100 *$ Bernardinus, c. 1.3 [p. 277D-E].

101 *Bernardinus, c. 1.5 [p. 277F-278A]. Tout comme Paschase Radbert dans *Adalhardus (voir n. 64 ci-dessus), Barnabé associe la prudence du saint à la capacité de tenir compte du passé, du présent et de l'avenir (praesentia, cum praeteritis comparans, quidquid futuri accidere poterat praemeditabatur), faisant allusion à Cicéron, De inventione, 2.53.160, ed. E. STRÖBEL (cf. supra, n. 10), p. 146. 
but des vertus cardinales, valeurs de la vie publique depuis l'Antiquité et employées pour glorifier les activités politiques des saints depuis l'ère carolingienne. On peut déceler une approche semblable dans deux Vies de Jean de Capistran. Son premier biographe déclare que Jean apprit au roi de Sicile à se conduire avec justice et équité de façon à mieux obliger les peuples sur lesquels il régnait; personnellement, le saint put gagner la bienveillance de tous par son respect des vertus cardinales, sa complaisance envers les bons et sa sévérité envers les méchants ${ }^{102}$. D'après le deuxième compte rendu de sa vie, Jean mit son sens de la justice au service de sa patrie en expulsant tous les malfaiteurs ${ }^{103}$. Le bien commun de la patrie, l'éradication du mal et des dissensions, la création d'un amour civique porté par tous: voilà les axes que suit la justice des saints, conformément aux préoccupations du Quattrocento. Par contre, d'après Bartholomé de Ferrare, la justice de Catherine de Sienne se manifestait avant tout dans la compassion et l'assistance sociale ${ }^{104}$ — notion sans doute plus adaptée dans le cas d'une sainte vivant à l'écart des affaires publiques.

Tout comme au Moyen Âge central, l'insistance sur le rôle politique des saints n'empêche nullement l'interprétation religieuse des vertus cardinales, même dans le cas de Bernardin. Dans le récit de Barnabé, le courage et surtout la tempérance du saint portent des connotations spirituelles et monastiques. Son courage se manifeste dans sa constance et sa persévérance pro fide et religione servanda: loin de reculer devant les dangers,

102 *Iohannes de Capistrano [1]: Erat enim hic Joannes Ladislao, Siciliae Regi, magnopere charus, adeoque illi morem gerere studebat, ut per justitiam et aequitatem continuo sibi creditos populos illi redderet cariores. Humanitate autem, prudentia, temperantia, fortitudine, munificentiaque ita praeditus fuit, ut omnium animos ad sui benevolentiam traheret atque impelleret, pius in bonos, severus in impios.

103 *Iohannes de Capistrano [2]: Zelo enim justitiae ejus latrones perterriti procul abscesserant, fures quoque et praedones necnon aliarum rerum invasores a patria exulaverat. Taceo caeteras ejus virtutes, quibus eum decoraverat Altissimus. Ita enim prudentia, temperantia, fortitudo, magnificentia, liberalitas et caeterae virtutes juvenem illum adornaverant, ut si singulas enarrare velim, timeo quod sermo noster nimis in longum protendatur.

104 *Catharina Senensis [1] [col. 1248]: Suo etiam modo de ejus justitia dici potest, omnibus \& unicuique quod suum est pro viribus exhibendo, prout ad justitiam spectat: tam ipsi Deo, quam sibi, quam etiam proximo, omnibus compatiens, omnibus subveniens, omnesque suo lato caritatis sinu suscipiens. Chacune des quatre vertus a un sens religieux dans ce sermon: par sa prudence, Catherine choisit la vie religieuse; par sa tempérance, elle menait une vie ascétique; par son courage, elle supportait avec gaieté toutes les adversités possibles au point de gagner une réputation de martyre. D'après la Legenda abbreviata, les paroles adressées à Catherine par le Christ ( $T u$ enim es illa que non es, ego vero sum ille qui sum) impliquent le respect des quatre vertus: Quis insuper prudentiam, qua ipsum summum bonum eligat, fortitudinem qua pro ipso summo bono cuncta substineat, iustitiam, qua declinet a malo et ipsum bonum sequatur, atque temperantiam, qua passiones moderetur ineptas, agiliter non eliciat ex prefata noticia? (*Catharina Senensis [2]). 
il endure humblement l'adversité pour le besoin de la foi, tandis que sa tempérance s'exprime à travers la chasteté et l'abstinence: refus absolu de contact avec les femmes en dehors de la sphère publique, limitation de la nourriture au strict nécessaire, observance minutieuse de tous les jeûnes ${ }^{105}$. Les références aux textes classiques et chrétiens se confondent dans ce contexte: parlant du courage de Bernardin, son hagiographe se réfère à la conception prétendument aristotélicienne de cette vertu (quam Peripatetici pericula subire dicunt). Dans d'autres sources hagiographiques contemporaines, c'est plutôt Macrobe qui donne le ton. Selon la Vie interpolée d'Aignan d'Orléans, les chanoines attachés à l'église du saint revendiquent certains terres en faisant appel à la justice, vertu qu'ils définissent avec toutes ses sous-espèces suivant les Commentarii in somnium Scipionis, en y ajoutant les trois autres vertus avec leurs ramifications. Si ces vertus accentuent leurs intérêts plutôt terrestres, elles vont de pair avec la vie spirituelle: Et si beatitudinem filiorum Dei et Ecclesie adhipisci volumus, expedit ut prudentiam, temperantiam, fortitudinem et ipsam iustitiam exerceamus ${ }^{106}$. Pour sa part, le chartreux Simon Zanacchi associa Ursuline de Parme aux quatre vertus dans un beau passage réarrangeant avec subtilité les définitions de Macrobe sur les trois niveaux humains de la vertu (virtutes politicae, virtutes purgatoriae, virtutes iam purgati animi), tout en mettant l'accent sur le caractère religieux de la justice: tam denique justa [sc. extitit], ut omnem animi sui cogitationem ad solum Deum dirigens, eum, tamquam omnium bonorum principium, medium ac finem fixa mentis acie intueretur. Dans son sermon sur Catherine de Sienne, Bartholomé de Ferrare assimilait même sa prudentia purgatoria sive purgati animi ${ }^{107}$ au degré héroïque de cette vertu requis dans les procès de canonisation! À la fin du Moyen Âge, les traditions classiques et chrétiennes des vertus cardinales allaient toujours ensemble dans l'hagiographie en se renforçant mutuellement, jusqu'au point de permettre des jeux de mots: rien n'était plus logique, assure l'hagiographe de Pierre de Luxembourg, que ce jeune saint, qui excellait dans les vertus cardinales, fût élevé au rang du cardinalat ${ }^{108}$.

\footnotetext{
$105 *$ Bernardinus, c. 1.4 [p. 277F].

$106 *$ Anianus [p. 273]; la formule fait entrevoir que l'on pourrait penser le contraire.

107 * Catharina Senensis [1], [col. 1249].

${ }^{108}$ Rationi denique fuit consentaneum, quod talis flos juventutis purpureus, ad cardinalatus sublimaretur fastigium, qui quatuor virtutes comprobatur habuisse cardinales. Le jeu de mots est plus subtil qu'il ne le paraît à première vue: Rationi ... consentaneum fait allusion à la définition de la vertu chez Cicéron, De inventione, 2.53.159, ed. E. STRÖBEL (cf. supra, $\mathrm{n}$. 10), p. 147: virtus est animi habitus naturae modo atque rationi consentaneus.
} 


\section{Conclusion}

Incontestablement, les vertus cardinales occupent une place importante dans les sources hagiographiques du Moyen Âge latin. Déjà présentes dans quelques Vies de saints composées à l'époque des Pères, les allusions aux quatre vertus vont constituer une véritable tradition hagiographique à partir de l'ère mérovingienne. En même temps, il faut constater que l'intégration des quatre vertus dans les Vies de saints n'a jamais pu s'affirmer comme règle. Même dans l'hagiographie du Moyen Âge central, qui fournit la plupart des références à nos vertus, celles-ci occupent toujours une position incertaine. À partir du XIII ${ }^{\mathrm{e}}$ siècle, le nombre de sources évoquant les vertus régresse brusquement; au XIV ${ }^{\mathrm{e}}$ siècle, cette tradition est moribonde. C'est seulement après 1400 qu'elle reprend une certaine vigueur, grâce notamment à l'intérêt tardif porté aux vertus cardinales par les moines mendiants italiens.

$\mathrm{Au}$ vu de ces données, il faut se garder de conclure trop rapidement que l'hagiographie médiévale a ouvert la chemin à l'introduction des vertus cardinales comme critère de sainteté dans les procès de canonisation. Juste avant 1200 , le schéma des quatre vertus connaît sa plus grande diffusion dans l'hagiographie; peu après 1200, au moment où la réserve papale des canonisations s'impose définitivement, le nombre des références aux vertus commence à reculer. Plutôt que de s'adapter à la tradition hagiographique que nous venons d'étudier, la politique papale des canonisations semble inciter les hagiographes à abandonner cette tradition et à affirmer la sainteté de leurs héros en termes alternatifs. Par contre, cette conclusion paraît plausible aux environs de l'an 1500. Le schéma des quatre vertus se réinstalle dans l'hagiographie au cours du Quattrocento pour enfin trouver une place - très aléatoire encore à la fin du siècle - dans les procès de canonisation, tendance fortement appuyée par les papes dans les siècles qui suivent. L'influence directe de notre tradition sur la conception de sainteté des Temps Modernes est donc limitée. Toujours est-il que le Moyen Âge a développé l'habitude d'associer les vertus cardinales à la perfection morale incarnée par ses saints, et que certains hagiographes ont même tissé autour de ces vertus la trame de la sainteté de leurs héros. Le fait que la moralité des croyants les plus exemplaires ait pu trouver son expression dans le schéma des vertus cardinales issu de l'Antiquité est une preuve solide de l'intégration heureuse de l'éthique ancienne et de la morale chrétienne dans l'Occident médiéval, non seulement dans les cercles académiques mais aussi dans l'imaginaire 
religieux et populaire. Si les hagiographes du Moyen Âge ne sont pas les meilleurs élèves de Platon, ils comptent parmi les divulgateurs les plus importants de certaines de ses idées.

Radboud Universiteit Nijmegen

Faculteit der Letteren

Postbus 9103

NL -6500 HD Nijmegen
István P. BEJCZY

Summary. Allusions to the cardinal virtues have been a hagiographic tradition since the beginning of the Middle Ages. Over one hundred Latin Vitae written before 1500 refer to the four virtues. Most of the references date from the 11th and 12th centuries; from the 13th century on the number of sources declines as the right to canonize is restricted to the popes and the Rota displays an apparent indifference to the cardinal virtues. After 1400 the theme of the four virtues once again becomes common in hagiography mostly because of mendicant Italian friars and is eventually included in the process of canonization in modern times.

\section{APPENDICE \\ LES SOURCES HAGIOGRAPHIQUES ÉVOQUANT LES VERTUS CARDINALES}

Nous donnons ci-dessous les références précises aux passages de sources hagiographiques qui mentionnent au moins trois vertus cardinales dans le même contexte. La plupart de ces sources sont répertoriées dans la $B H L$, qui ne nous a pourtant pas servi de guide exclusif. Par ailleurs, nous n'avons pas inclus le Septililium de Dorothée de Montau ( $B H L$ 2326), même si le chapitre 7.19 de cet ouvrage traite des vertus cardinales; à notre avis, il ne s'agit pas ici d'un texte hagiographique et, de surcroît, le chapitre 7.19 est rédigé en allemand. Il existe naturellement de nombreux textes non hagiographiques qui parlent des saints et de leurs vertus; le fait qu'un saint ne figure pas dans cette liste ne signifie donc nullement qu'on n'ait pas associé, à un moment ou l'autre du Moyen Âge, ce saint aux vertus cardinales. 
*Adalbertus ep. Pragensis (vers 956-997).

Bruno de Querfurt, Vie (BHL 38, 39); datation: 1004/1008.

Ed. J. KARWASIŃSKA, in Monumenta Poloniae Historica, n. s., t. IV/2, Varsovie, 1969, p. 16 (BHL 38), 54 (BHL 39).

*Adalhardus ab. Corbeiensis (753-827).

Paschase Radbert, Vie (BHL 58); datation: peu après 827.

Ed. J. MABILLON, in PL 120, col. 1517.

*Altmannus ep. Pataviensis (vers 1015-1091).

Vie anonyme (BHL 313); datation: vers 1140.

Ed. W. WATTENBACH, $M G H, S S, 12$, Hanovre, 1856, p. 235 (c. 18).

*Ama ( $\mathrm{V}^{\mathrm{e}} \mathrm{s}$.).

Étienne de Saint-Urbain, Vie (non recensée dans la $B H L$ ); datation: vers 1050/1060?

Ed. F. DOLBEAU, Vie latine de sainte Ame, composée au XIT siècle par Étienne, abbé de Saint-Urbain, in $A B, 105$ (1987), p. 53-54 (c. 13.5-6).

*Amalberga ( $\mathrm{VII}^{\mathrm{e}} / \mathrm{VIII}^{\mathrm{e}} \mathrm{s}$.).

Radbod d'Utrecht, Sermon (BHL 322); datation: avant 917.

Ed. $A A S S$, Iul. t. 3, p. $89 \mathrm{~F}\left[3^{\mathrm{e}}\right.$ ed., p. $\left.86 \mathrm{E}\right]$ (c. 7).

*Amantius erem. in Silva Buxea (VI s.).

Hugues d'Angoulême (?), Vie (BHL 350); datation: avant 990/994?

Ed. $A B, 8$ (1889), p. 333-335 (c. 3-4).

*Anianus ep. Aurelianensis ( $\uparrow 453)$.

Miracula anonymes, interpolés ( $B H L$ 476d); datation: $\mathrm{XV}^{\mathrm{e}} \mathrm{s}$. (interpolations).

Ed. G. RENAUD, Les Miracles de saint Aignan d'Orléans (XI' siècle), in AB, 94 (1976), p. 273-274 (c. 18).

*Ansegisus ab. Fontanellensis (vers 770-833).

Vie anonyme $(B H L 524)=$ Gesta abbatum Fontanellensium, c. 17; datation: vers $833 / 850$.

Ed. S. LÖWENFELD, MGH. Scriptores rerum Germanicarum in usum scholarum separatim editi, 28, Hanovre, 1886, p. 51 (c. 17).

*Antoninus ep. Florentinus (1389-1459).

Francesco Castiglione, Vie (BHL 577); datation: vers 1471.

Ed. $A A S S$, Maii t. 1, p. 322D [ $3^{\mathrm{e}}$ ed., p. 326E] (c. 4.30).

*Antonius ab. in Thebaide ( $\$ 356)$.

[1] Traduction anonyme de la Vie d'Athanase (BHL 609e); entre 357 et 370/375.

Ed. G. J. M. BARTELINK, Vita di Antonio (= Scrittori greci e latini. Vite dei santi, 1), Milan, 1974, p. 44 (c. 17.7).

[2] Évagre d'Antioche, traduction de la Vie d'Athanase (BHL 609); datation: vers 370/375.

Ed. $A A S S$, Ian. t. 2, p. $125\left[3^{\text {e }}\right.$ ed., p. 490$]$ (c. 5.29). 
*Apianus mon. Papiae (VIII $/ \mathrm{IX}^{\mathrm{e}} \mathrm{s}$.).

Sermon anonyme (BHL 620); datation: avant 1100.

Ed. $A A S S$, Mart. t. 1, p. 325A-C [ $3^{\text {e }}$ ed., p. 322E-323A] (c. 4).

*Audoenus ep. Rotomagensis (vers 600-684).

Vie anonyme (BHL 751); datation: $\mathrm{IX}^{\mathrm{e}} \mathrm{s}$.

Ed. $A A S S$, Aug. t. 4, p. $810 \mathrm{C}$ (prol.).

*Augustinus ep. Hipponensis (354-430).

[1] Hilduin (chancelier de l'Université de Paris), Sermo de sancto Augustino ad canonicos regulares (non recensé dans la $B H L$ ); datation: 1178/1190.

Manuscrit Paris, Mazarine 774, f. $182^{\text {ra }}$.

[2] Alain de Lille, Sermo in natali sancti Augustini (non recensé dans la BHL); datation: avant 1203.

Ed. M.-Th. d'AlVERNY, Alain de Lille. Textes inédits (= Etudes de philosophie médiévale, 52), Paris, 1965, p. 264-265.

*Barlaam et Josaphat (?).

Adaptation latine (BHL 979$)$ de la Vie grecque de Jean Damascène; datation: après 1050.

Ed. O. DE LA CRUZ PALMA, Barlaam et Iosaphat, versión vulgata latina (= Nueva Roma, 12), Madrid - Bellaterra, 2001, p. 320 (c. 19).

*Berardus ep. Marsorum (1079-1130).

Jean de Sainte-Sabine des Marses, Vie (BHL 1176); datation: peu après 1130.

Ed. AASS, Nov. t. $2 / 1$, p. 130C-E (c. 1.3).

*Bernardinus Senensis (1380-1444).

Barnabé de Sienne, Vie (BHL 1188); date: 1445.

Ed. $A A S S$, Maii t. 5, p. $277^{*}$ D-278*B [ $3^{\text {e }}$ ed., p. $108^{*}$ A-E] (c. $\left.1.3-5\right)$.

*Bernardus ab. Claravallensis (1090-1153).

Geoffroy d'Auxerre, Vita (prima) Bernardi (BHL 1220); datation: vers 1155.

Ed. $A A S S$, Aug. t. 4, p. 298C (1. III, c. 1.159).

*Bernardus ab. Tironiensis (vers 1050-1117).

Geoffroy le Gros, Vie (BHL 1251); datation: entre 1137 et 1149.

Ed. AASS, Apr. t. 2, p. 246F-247A [3 $3^{\mathrm{e}}$ ed., p. 246C-E] (c. 11.103-104).

${ }^{*}$ Bertuinus ep. Maloniae (VII $\mathrm{e}$ s.?).

Vie anonyme ( $B H L$ 1306); datation: vers 800 .

Ed. W. LEVISON, MGH, SRM, 7, Hanovre - Leipzig, 1920, p. 178 (c. 1).

*Bonaventura (1221-1274).

Jean-François Pavini, Relatio (non recensée dans la $B H L$ ); date: 1482.

Ed. dans Bonaventure, Opuscula, t. 2, Strasbourg, 1495, f. $5^{\text {va }}-20^{\text {va }}$.

*Bononius ab. Lucediensis $(\dagger 1026)$.

Vie anonyme ( $B H L$ 1421); datation: peu après 1026.

Ed. G. SCHWARTZ - A. HOFMEISTER, MGH, SS, 30/2, Leipzig, 1934, p. 1026 (c. 2). 
*Brigida Kildariae (VIr ${ }^{\mathrm{e}} \mathrm{s}$.).

Laurent de Durham, Vie (BHL 1461); datation: avant 1154.

Ed. W. W. HEIST, Vitae sanctorum Hiberniae (= Subs. hag., 28), Bruxelles, 1965, p. 7 (c. 16).

*Catharina Senensis (1347-1380).

[1] Bartholomé de Ferrare, Sermon; date: 1411.

Ed. E. MARTĖNE - U. DURAND, Processus contestationum super sanctitate et doctrina beatae Catharinae de Senis (BHL 1707), dans Veterum scriptorum et monumentorum ... collectio, t. 6, Paris, 1729, col. 1248-1250.

[2] Thomas Caffarini, Legenda minor (BHL 1704c, 1740d); datation: entre 1416 et 1434.

Ed. E. FRANCESCHINI, Sanctae Catharinae Senensis Legenda minor (= Fontes Vitae S. Catharinae Senensis historici, 10), Sienne - Milan, 1942, p. 30 (1704c), p. 31 (1704d).

[3] Epitome vitae anonyme (BHL, suite à 1709); datation: avant 1474.

Ed. Th. GRAESSE, dans Jacques de Voragine, Legenda aurea, Breslau, 1890, p. 945 (appendice, c. 231/202).

* Clara de Cruce (1268-1308).

Procès de canonisation; témoignage de son frère Francesco (non recensé dans la $B H L$ ); datation: $1318 / 1319$.

Ed. E. MENESTò, Il processo di canonizzazione di Chiara da Montefalco (=Quaderni del «Centro per il Collegamento degli Studi Medievali e Umanistici nell'Università di Perugia», 14), Scandicci - Perugia, 1984, p. 269-272.

*Crescentius subdiac. Florentiae $\left(\mathrm{IV} / \mathrm{v}^{\mathrm{e}} \mathrm{s}\right.$.).

Elogium vitae anonyme (BHL 1984); datation: bien après le XI ${ }^{\mathrm{e}} \mathrm{s}$.

Ed. $A A S S$, Apr. t. 2, p. $625 \mathrm{~A}\left[3^{\mathrm{e}}\right.$ ed., p. $\left.621 \mathrm{~F}-622 \mathrm{~A}\right]$ (c. 6).

*Decorosus ep. Capuanus ( $\dagger 695)$.

Vie anonyme (BHL 2117); date incertaine.

Ed. AASS, Febr. t. 2, p. 842C-D [3 ${ }^{\text {e }}$ ed., p. 842B] (lectio 3).

*Desiderius ep. Cadurcensis ( $\dagger$ vers 655 ).

Vie anonyme (BHL 2143); datation: vers 800.

Ed. B. KRUSCH, Corpus Christianorum. Series Latina, 117, Turnhout, 1957, p. 369 (c. 21).

*Dodo ab. Waslerensis ( $\dagger$ vers 750 ).

Vie anonyme ( $B H L$ 2207); datation: peu après 980.

Ed. $A A S S$, Oct. t. 12 , p. $635 \mathrm{~B}$ (c. 1.4).

*Droctoveus ab. Parisiensis (vers 530-vers 580).

Gislemar de Saint-Germain, Vie (BHL 2336); datation: vers 841/847.

Ed. B. KRUSCH, $M G H$, SRM, 3, Hanovre, 1896, p. 539 (c. 8). 
*Edmundus Rich (vers 1180-1240).

[1] Eustache de Faversham, Vie (BHL 2412d-e); datation: 1242/1244.

Ed. C. H. LAWrenCE, St. Edmund of Abingdon: A Study in Hagiography and History, Oxford, 1960 (réimpr. 2000), p. 210.

[2] Quadrilogus anonyme (BHL 2412); date: 1244.

Ed. LAWRENCE, p. 198.

[3] Matthieu Paris, Vie (BHL 2405); datation: 1250/1253.

Ed. LAWRENCE, p. 233-234 (c. 9); passage repris de [1].

${ }^{*}$ Egwinus ep. Wigorniensis $(\dagger 717$ ?).

Dominique d'Evesham, Vie (BHL 2433); datation: avant 1100 ? (livre 1).

Ed. M. LAPIDGE, Dominic of Evesham «Vita S. Ecgwini episcopi et confessoris», in $A B, 96$ (1978), p. 79 (c. 1.2).

*Eligius ep. Noviomensis (588/590-660).

Ouen de Rouen, Vie (BHL 2474-2476) adaptée; datation: $1^{\mathrm{e}} \mathrm{m}$. VIII $\mathrm{e}$ s. (adaptation). Ed. PL 87, col. 519C-D (c. 2.9).

*Elisabeth landgr. Thuringiae (1207-1231).

Césaire d'Heisterbach, Sermo de translatione (BHL 2495); date: 1237.

Ed. A. HuYskens, in A. HILKA et al., Die Wundergeschichten des Caesarius von Heisterbach (= Publikationen der Gesellschaft für Rheinische Geschichtskunde, 43), t. 3, Bonn, 1937, p. 382 (c. 1-2).

*Emmerammus m. (fin $\mathrm{VII}^{\mathrm{e}} \mathrm{s}$.).

Arnold de Saint-Emmeran, De miraculis et memoria Emmerammi (BHL 2541); datation: 1035/1037.

Ed. G. WAITZ, $M G H, S S$, 4, Hanovre, 1841, p. 560-561 (c. 2.14).

*Eparchius recl. Engolismensis (504-581).

Miracles anonymes (BHL 2561); datation: $\mathrm{IX}^{\mathrm{e}} \mathrm{s}$.

Ed. B. KRUSCH, MGH, SRM, 3, Hanovre, 1896, p. 564 (c. 17).

*Eusebia abb. Hammaticensis ( $\dagger$ vers 680 ).

Vie anonyme (BHL 2736); datation: vers 1000.

Ed. AASS, Mart. t. 2, p. 454C-D [3 ed., p. 449D] (c. 2.11).

*Eustadiola abb. Bituricensis ( $\dagger$ vers 690 ).

Vie anonyme (BHL 2772); datation: début VIII $\mathrm{s}$.

Ed. AASS, Iun. t. 2, p. 134B [ $3^{\mathrm{e}}$ ed., p. 132E] (c. 6).

*Fides v. m. (III ${ }^{\mathrm{e}} \mathrm{s}$.).

Bernard d'Angers, Miracles (BHL 2942); datation: 1013-1020.

Ed. L. ROBERTINI, Liber miraculorum sancte Fidis. Edizione critica e commento (= Biblioteca di «Medioevo Latino», 10), Spoleto, 1994, p. 81 (1. I, c. 1).

*Florentius presb. in Glonna monte ( $\mathrm{V}^{\mathrm{e}} / \mathrm{VII}^{\mathrm{e}} \mathrm{s}$.?).

Marbode de Rennes, Sermon (BHL 3050); datation: avant 1123, peut-être avant 1096.

Ed. $A A S S$, Sept. t. 6, p. 434E-436F (c. 2.12-23). 
*Francisca Romana (1384-1440).

Visions (BHL 3094) rédigées par Jean Matteotti; datation: vers 1440.

Ed. A. BARTOLOMEI ROMAGNOLI, S. Francesca Romana. Edizione critica dei trattati latini di Giovanni Mattiotti (= Storia e attualità, 14), Cité du Vatican, 1994, p. 457 (Visio XVI, 74), 566 (Visio XXXIX, 87), 597 (Visio XLVII, 22), 694-695 (Visio LXXVIII, 12-16), 730 (Visio CVIII, 14).

*Furseus ab. Latiniacensis ( $\dagger$ vers 649).

Vie anonyme (BHL 3209); datation: $\mathrm{VII}^{\mathrm{e}} \mathrm{s}$.

Ed. M. P. CICCARESE, Le visioni di S. Fursa, in Romanobarbarica, 8 (1984-85), p. 279 (c. 1).

*Gerardus ab. Broniensis ( $†$ 959).

Vie anonyme (BHL 3422); datation: 1074/1075.

Ed. L. DE HEINEMANN, MGH, SS, 15, Hanovre, 1888, p. 668 (c. 18).

${ }^{*}$ Gildas ab. Ruiensis ( $†$ vers 570 ).

Vital de Rhuys, Vie (BHL 3541); datation: vers 1060.

Ed. F. LoT, Gildae Vita et Translatio, in Annales de Bretagne, 25 (1909-10), p. 501 (c. 29).

*Goswinus ab. Aquicinctinus ( $†$ 1166).

Poème anonyme (non recensé dans la $B H L$ ); datation: peu après 1166 .

Ed. J. LeCLERCQ, Poèmes à la louange de S. Gossuin d'Anchin, in AB, 100 (1982), p. 630 (Poème XIII, v. 3-6).

*Gregorius I papa (r. 590-604).

Tajon de Sarragosse, Lettre à Eugène II de Tolède (non recensée dans la $B H L$ ); datation: $651 / 657$.

Ed. F. VOLLMER, MGH, Auctores antiquissimi, 14, Hanovre, 1905, p. 288 (Ep. 4.9).

*Gregorius VII papa (r. 1073-1085).

[1] Hugues de Flavigny, Chronicon (passage non recensé dans la $B H L$ ); datation: $1090 / 1102$.

Ed. G. H. PeRTZ, MGH, SS, 8, Hanovre, 1848, p. 424 (1. 2).

[2] Paul de Bernried, Vie (BHL 3652); date: 1128.

Ed. $A A S S$, Maii t. 6, p. 117A [ $3^{\mathrm{e}}$ ed., p. 116A] (c. 3.21).

*Gudila Bruxellis († 712?).

[1] Hubert (de Bruxelles? de Lobbes?), Vie (BHL 3684); datation: vers 1100.

Ed. AASS, Ian. t. 1, p. 515 (c. 1.6).

[2] Vie anonyme (BHL 3685); datation: $\mathrm{XII}^{\mathrm{e}} / \mathrm{XIII}{ }^{\mathrm{e}} \mathrm{s}$.

Ed. $A A S S$, Ian. t. 1, p. 524 (c. 1.5); passage repris de [1].

*Guthlacus erem. (674-714).

Félix de Jarrow, Vie (BHL 3723); datation: vers 730/740.

Ed. B. Colgrave, Felix's Life of St. Guthlac, Cambridge, 1956 [réimpr. 1985], p. 84 (c. 21). 
*Helena imperatrix $(† 328 / 330)$.

Alman de Hautvillers, Vie (BHL 3772); datation: avant 889.

Ed. AASS, Aug. t. 3, p. 581E (prol.).

*Hilarius ep. Arelatensis (vers 400-449).

Honorat de Marseille, Vie (BHL 3882); datation: 470/480.

Ed. S. CAVAllin, Vitae sanctorum Honorati et Hilarii episcoporum Arelatensium (= Skrifter Utgivna av Vetenskaps-Societeten i Lund, 40), Lund, 1952, p. 84-85 (c. 5).

*Hilarius Auciacensis (IV ${ }^{\mathrm{e}}$ s. ?).

Vie anonyme ( $B H L$ 3882d); datation: $\mathrm{XII}^{\mathrm{e}} \mathrm{s}$.

Ed. M. COENS, in $A B, 39$ (1921), p. 107 (c. 6).

*Hildegardis regina (vers 758-783).

Vie anonyme (BHL 3934-3935); datation: avant 1472.

Ed. $A A S S$, Apr. t. 3, p. $793 \mathrm{~F}\left[3^{\mathrm{e}}\right.$ ed., p. $\left.803 \mathrm{~A}\right]$ (c. 1.1 ).

*Hugo ep. Gratianopolitanus (1053-1132).

Guigues de Saint-Romain, Vie (BHL 4016); datation: 1134/1135.

Ed. $A A S S$, Apr. t. 1, p. $43 \mathrm{E}$ [ $3^{\mathrm{e}}$ ed., p. $\left.44 \mathrm{~A}\right]$ (c. 5.23).

*Iacobus Maior ( $†$ 44).

Pseudo-Calixte II, Sermon (cf. BHL 4076a); datation: 1139/1173.

Ed. W. M. WHITEHILL, Liber sancti Jacobi. Codex Calixtinus, t. 1, Saint-Jacquesde-Compostelle, 1944, p. $50=$ PL 163, col. 1397D-1398A.

*Iohannes Bassandus (1360-1445).

Vie anonyme (BHL 4336); datation: peu après 1445.

Ed. AASS, Aug. t. 5, p. 879F (c. 2.21).

*Iohannes de Capistrano (1386-1456).

[1] Nicolas (Tellus) de Fara, Vie (BHL 4360); datation: 1461/1462.

Ed. AASS, Oct. t. 10, p. 440E (c. 1.3).

[2] Christophe Picinelli de Varèse, Vie (BHL 4363); datation: 1462/1463.

Ed. AASS, Oct. t. 10 , p. $492 \mathrm{C}$ (c. 1.3).

*Isidorus ep. Hispalensis (vers 560-636).

Lucas de Tuy, Vie (BHL 4486); datation: vers 1200.

Ed. AASS, Apr. t. 1, p. 335F, 350B [ $3^{\mathrm{e}}$ ed., p. 337B-C, $\left.348 \mathrm{~B}\right]$ (c. $4.17,10.37$ ).

*Ivo Trecorensis (1253-1303).

Maurice Gaufridus, Vie (BHL 4637); datation: 1465/1479.

Ed. $A A S S$, Maii t. 4, p. 589D [3 $3^{\text {e }}$ ed., p. 590A-B] (c. 3.32).

*Lambertus ep. Traiectensis ( $†$ vers 705 ).

[1] Miracula anonymes (BHL 4689); datation: 850/920.

Ed. J. DeMARTEAU, Saint Lambert. Vie écrite en vers par Hucbald de Saint-Amand et documents $d u X^{e}$ siècle, in Bulletin de l'Institut archéologique liégeois, 13 (1877), p. 517 (c. 2). 
[2] Étienne de Liège, Vie (BHL 4683); datation: 901/920.

Ed. AASS, Sept. t. 5, p. 586D-E (c. 3.26).

*Lambertus ep. Venciensis ( $† 1154)$.

Vie anonyme (BHL 4695); datation: peu après 1154.

Ed. $A A S S$, Maii t. 6, p. 459A-B [3e ed., p. 454E-F] (c. 2).

*Liebertus ep. Cameracensis $(\dagger 1076)$.

Raoul du Saint-Sépulcre, Vie (BHL 4929); datation: vers 1100.

Ed. A. HofMEISTER, MGH, SS, 30, Hanovre - Leipzig, 1926-1934, p. 852 (c. 25).

*Lucius I papa (†254).

Guaiferius du Mont Cassin, Vie (BHL 5022); datation: avant 1073/1078.

Ed. O. LIMONE, L'opera agiografica di Guaiferio di Montecassino, in Monastica III (= Miscellanea Cassinese, 47), Montecassino, 1983, p. 120 (c. 8).

*Lupus ep. Trecensis ( $†$ vers 478/479).

[1] Vie anonyme (BHL 5089); datation: vers 800.

Ed. $A A S S$, Iul. t. 7 , p. $73 \mathrm{D}\left[3^{\mathrm{e}}\right.$ ed., p. $\left.84 \mathrm{E}\right]$ (c. 1.11 ).

[2] Hugues de Flavigny, Chronicon (passage non recensé dans la $B H L$ ); datation: 1090/1102.

Ed. G. H. PERTZ, MGH, SS, 8, Hanovre, 1848, p. 310-311 (1. 1).

*Magdalveus ep. Virodunensis ( $† 777 / 781)$.

Hugues de Flavigny, Chronicon (BHL 5133); datation: 1090/1102.

Ed. G. H. PERTZ, MGH, SS, 8, Hanovre, 1848, p. 341 (1. 1).

*Maiolus ab. Cluniacensis († 994).

[1] Odilon de Cluny, Vie (BHL 5182); date: 1033.

Ed. $A A S S$, Maii t. 2, p. 687 C-D [ $3^{\mathrm{e}}$ ed., p. 685E-F] (c. 1.9$)$.

[2] Odilon de Cluny, Appendix ou Libri miraculorum (BHL 5183); datation: peu après 1033.

Ed. AASS, Maii t. 2, p. 695B-C [3e ed., p. 693D-E] (c. 1.2).

*Malachias ep. Armacanus (1094-1148).

Bernard de Clairvaux, Vie (BHL 5188); datation: 1148/1152.

Ed. J. LeCleRCQ - H.-M. RochaIS, S. Bernardi Opera, t. 3, Rome, 1963, p. 345 (c. 40).

*Mathildis praep. Diessensis $(\dagger 1160)$.

Engelhard de Langheim, Vie (BHL 5686); datation: vers 1200.

Ed. $A A S S$, Maii t. 7, p. 447A [ $3^{\text {e }}$ ed., p. 439C] (c. 1.9).

*Mauritius et soc. mm. Thebaei ( $† 285$ ou 302$)$.

Sigebert de Gembloux, Passio sanctorum Thebeorum (BHL 5754); datation: vers 1074.

Ed. E. DÜMMLER, Sigebert's von Gembloux Passio sanctae Luciae virginis und Passio sanctorum Thebeorum, in Abhandlungen der königl. preußischen Akademie der Wissenschaften zu Berlin. Phil.-hist. Classe, 1 (1893), p. 106 (1. 3, v. 396-400). 
*Meinulphus diac. Paderbornensis ( $†$ 847/857).

Gobelinus Persona (Gobele Person), Vie (BHL 5883); datation: 1409/1416.

Ed. $A A S S$, Oct. t. 3, p. 219A-B (c. 1.10).

*Modoaldus ep. Treverensis (614/615-647/649).

Étienne II de Saint-Jacques de Liège, Vie (BHL 5984); datation: vers 1100.

Ed. $A A S S$, Maii t. 3, p. 52D [3 ${ }^{\text {e }}$ ed., p. 53B] (c. 1.6).

*Notkerus Balbulus (vers 840-912).

Ekkehard de Saint-Gall, Vie (BHL 6251); datation: vers 1220/1240.

Ed. $A A S S$, Apr. t. 1, p. 591D [3 ${ }^{\mathrm{e}}$ ed., p. 588F-589A] (c. 5.38).

*Odilo ab. Cluniacensis (961/962-1048/1049).

Jotsald de Cluny, Vie (BHL 6281); datation: 1051/1052.

Ed. J. STAUB, MGH. Scriptores rerum Germanicarum in usum scholarum separatim editi, 68, Hanovre, 1999, p. 154-169 (c. 1.5-13).

*Oswaldus rex $(\dagger 642)$.

Drogon de Bergues-Saint-Winnoc, Vie (BHL 6362); datation: avant 1070.

Ed. $A A S S$, Aug. t. 2, p. $99 \mathrm{~A}-\mathrm{B}$ (c. 3.25 ).

*Paternianus ep. Fanensis (IV $\mathrm{e}$ s.?).

Vie anonyme (BHL 6472); datation: $\mathrm{X}^{\mathrm{e}} / \mathrm{XI}^{\mathrm{e}} \mathrm{s}$.

Ed. S. PRETE, Note critiche alla Vita S. Paterniani, in Studia Picena, 38/2 (197071), p. 19 (c. 15).

*Paulus Novus ( $† 766)$.

Translatio (BHL 6592); datation: vers 1222.

Ed. $A A S S$, Iul. t. 2, p. $640 \mathrm{D}\left[3^{\mathrm{e}}\right.$ ed., p. $\left.640 \mathrm{C}\right]$ (c. 5 )

*Petrus de Luxemburgo (1369-1387).

Vie anonyme (BHL 6719); datation: peu après 1387.

Ed. $A A S S$, Iul. t. 1, p. $514 \mathrm{E}\left[3^{\mathrm{e}}\right.$ ed., p. $\left.453 \mathrm{~B}\right]$ (c. 5.30$)$.

*Petrus Monoculus $(\dagger 1186)$.

Thomas de Reuil, Vie (BHL 6730); date: 1204.

Ed. AASS, Oct. t. 13, p. 73C, 79D-80A (c. 2.13.22, 3.25.52).

*Petrus de Murrone (Caelestinus V papa, r. 1294; 1209/1210-1296).

Jacques Gaetani Stefaneschi, Opus metricum: De canonizatione Petri Caelestini (BHL 6749); datation: vers 1315.

Ed. F. X. SEPPELT, Monumenta Coelestiniana (= Quellen und Forschungen aus dem Gebiete der Geschichte ... der Görres-Gesellschaft, 19), Paderborn, 1921, p. 123 (c. 1.14).

*Petrus Trebanus $\left(\mathrm{XI}^{\mathrm{e}} / \mathrm{XII}{ }^{\mathrm{e}} \mathrm{s}\right.$.).

Vie anonyme (BHL 6783); datation: $\mathrm{XI}^{\mathrm{e}} / \mathrm{XII}^{\mathrm{e}} \mathrm{s}$.

Ed. $A A S S$, Aug. t. 6, p. 641F-642B (c. 1.7-8). 
*Radegundis regina (vers 520-587).

Hildebert de Lavardin, Vie (BHL 7051); datation: avant 1133.

Ed. AASS, Aug. t. 3, p. $90 \mathrm{C}-\mathrm{D}$ (c. 4.39).

*Ragenufla v. (VII $\mathrm{e}$. ?).

Vie anonyme ( $B H L$ 7056); datation: vers 1150.

Ed. $A A S S$, Iul. t. 3, p. 697A [3 ${ }^{\mathrm{e}}$ ed., p. 667E] (c. 1.3).

*Rainaldus ep. Ravennas (1240/1250-1321).

Nicolas de Rimini, Vie (BHL 7081); date: 1413.

Ed. $A A S S$, Aug. t. 3, p. 694F-695A (c. 2.14).

*Restituta v. m. († 304?).

Pierre de Naples, Passion (BHL 7190); datation: $\mathrm{X}^{\mathrm{e}} \mathrm{s}$.

Ed. E. D'ANGELO, Pietro suddiacono Napoletano. L'opera agiografica (= Edizione nazionale dei testi mediolatini, 7), Florence, 2002, p. 189-190, 195.

*Richardus ep. Cicestrensis (vers 1197-1253).

Ralph Bocking, Vie (BHL 7209; KAEPPELI 3387); datation: vers 1270.

Ed. D. JONES, Saint Richard of Chichester. The Sources of his Life (= Sussex Record Society, 79), Lewes, 1995, p. 108-110 (c. 23).

*Richardus ab. S. Vitoni († 1046).

Hugues de Flavigny, Chronicon (BHL 7219); datation: 1090/1102.

Ed. G. H. PERTZ, MGH, SS, 8, Hanovre, 1848, p. 380 (1. 2).

*Richarius ab. Centulensis ( $\dagger$ vers 650 ).

Vie anonyme (BHL 7245); datation: $2^{\mathrm{e}} \mathrm{m}$. VII ${ }^{\mathrm{e}} \mathrm{s}$ ?

Ed. B. KRUSCH, $M G H$, SRM, 7, Hanovre - Leipzig, 1920, p. 446 (c. 4).

*Rictrudis abb. Marchianensis (vers 614-687).

Hucbald de Saint-Amand, Vie (BHL 7247); date: 907.

Ed. $A A S S$, Maii t. 3, p. 84D [3 $3^{\mathrm{e}}$ ed., p. $\left.84 \mathrm{~A}-\mathrm{B}\right]$ (c. 2.13).

*Romanus ep. Rotomagensis (fl. vers 629).

Gérard de Soissons, Vie (BHL 7312); datation: avant 989.

Ed. $A A S S$, Oct. t. 10, p. 93A-B (prol.).

*Sacerdos ep. Lemovicensis ( $†$ vers 700 ?).

Hugues de Fleury, Vie (BHL 7456-7459); datation: avant 1119/1120.

Ed. $A A S S$, Maii t. 2, p. $15 \mathrm{~B}\left[3^{\mathrm{e}}\right.$ ed., p. $\left.15 \mathrm{~F}\right]$ (c. 1.5$)$.

*Satyrus Mediolanensis (vers 330-377/378).

Ambroise de Milan, De excessu fratris Satyri (BHL 7509); date: 378.

Ed. O. FALLER, Corpus Scriptorum Ecclesiasticorum Latinorum, 73, Vienne, 1955, p. 232-241 (c. 1.42-62).

*Silvinus ep. ( $\dagger$ vers 720$)$.

Anténor, Vie (BHL 7747) adaptée; datation: VIII $/ \mathrm{IX}^{\mathrm{e}} \mathrm{s}$. (adaptation).

Ed. $A A S S$, Febr. t. 3, p. $30 \mathrm{C}\left[3^{\mathrm{e}}\right.$ ed., p. 30A] (c. 1.11). 
*Stephanus inst. Ord. Grandimontensis ( $† 1124)$.

[1] Gérard Ithier, Vie (BHL 7904); datation: 1188/1198.

Ed. J. BECQUET, Corpus Christianorum. Continuatio Medievalis, 8, Turnhout, 1968, p. 319 (c. 1).

[2] Odon de Grandmont, Versus de virtutibus Stephani Muretensis (non recensés dans la $B H L)$; datation: vers 1200 .

Ed. BECQUET, p. 253 (v. 9-10); passage repris de [1].

*Thomas Aquinas (1225-1274).

Antonio Pizamano, Legenda (BHL 8160); date: 1490.

Ed. in Thomas d'Aquin, Opuscula, Venise, 1490, f. $4^{\text {va }}$.

*Thomas ep. Cantuariensis (vers 1118-1170).

William FitzStephen, Vie (BHL 8176); datation: 1173/1176.

Ed. J. C. ROBERTSON - J. B. SHEPPARD, Materials for the History of Thomas Becket, Archbishop of Canterbury (= Rerum Britannicarum Medii Aevi scriptores, 67), t. 3, Londres, 1877 , p. 39-40 (c. 28 ).

*Thomas Florentinus (1370-1447).

Pierre Marin Morelli, Vie (BHL 8251); datation: peu après 1447.

Ed. $A A S S$, Oct. t. 13 , p. 883 C-D (c. 5.45 )

*Tillo mon. Sollemniacensis († 702).

Vie anonyme (BHL 8291); date incertaine.

Ed. $A A S S$, Ian. t. 1, p. 379 (c. 21).

*Trudo ab. in Hasbania († vers 693).

Donat de Metz, Vie (BHL 8321); datation: 775/800.

Ed. W. LEVISON, MGH, SRM, 6, Hanovre - Leipzig, 1913, p. 285 (c. 12).

*Turiavus ab. Dolensis (VIII ${ }^{\mathrm{e}} \mathrm{s} . ?$ ).

Vie anonyme (BHL 8342); datation: $\mathrm{X}^{\mathrm{e}} \mathrm{s}$.

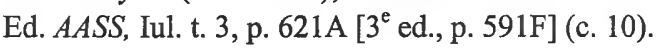

*Ursmarus ab. Lobiensis (697-713).

[1] Anson de Lobbes, Vie (BHL 8416); datation: 776/800.

Ed. W. LEVISON, MGH, SRM, 6, Hanovre - Leipzig, 1913, p. 455 (c. 2).

[2] Rathier de Vérone, Vie (BHL 8417); datation: vers 940.

Ed. $P L$ 136, col. 348 A (c. 3).

[3] Hériger de Lobbes, Vie rythmique (BHL 8419); datation: avant 980.

Ed. K. STRECKER, MGH, Poetae latini, 5, Hanovre - Leipzig, 1937-39, p. 197-198 (1. 1, v. 642-644).

[4] Hériger de Lobbes (?), Hymne (BHL 8425b).

Ed. K. STRECKER, MGH, Poetae latini, 5, p. 209 (strophe 10).

*Ursula et sociae ( $\dagger$ vers 304$)$.

Sermo in natali SS. virginum XI millium anonyme (BHL 8426); datation: $1^{\mathrm{e}} \mathrm{m} . \mathrm{X}^{\mathrm{e}} \mathrm{s}$. Ed. AASS, Oct. t. 9, p. 155E (c. 11). 
*Ursulina Parmensis (1375-1408/1410).

Simon Zanacchi, Vie (BHL 8452); datation: 1472.

Ed. $A A S S$, Apr. t. 1, p. 736A-D [3 ${ }^{\mathrm{e}}$ ed., p. 731F-732B] (c. 5.42-43).

*Victor presb. Archiaci ( $\mathrm{V}^{\mathrm{e}} / \mathrm{VII}^{\mathrm{e}} \mathrm{s}$. ?).

Bernard de Clairvaux (1090-1153), Sermo in natali Victoris (non recensé dans la $B H L)$; datation: $1145 / 1151$ ?

Ed. J. LeCLERCQ - H.-M. RochaIS, S. Bernardi Opera, t. 6/1, Rome, 1970, p. 32 (c. 1.5).

*Wala ab. Corbeiensis (vers 755-836).

Paschase Radbert, Vie ( $B H L$ 8761); datation: peu après 836 (livre 1), vers 852/865 (livre 2).

Ed. E. DÜMMLER, Radbert's Epitaphium Arsenii (= Abhandlungen der königl. preußischen Akademie der Wissenschaften zu Berlin. Phil.-hist. Classe, 2 (1900), p. 30-31 (c. 2.7).

*Walaricus ab. Leuconaensis (vers 565-619/622).

Vie anonyme (BHL 8762); datation: $\mathrm{XI}^{\mathrm{e}} \mathrm{s}$.

Ed. B. KRUSCH, $M G H$, SRM, 4, Hanovre - Leipzig, 1902, p. 162 (c. 3).

*Waldburgis abb. Heidenheimensis (vers 710-779).

Philippe de Rathsamhausen, Vie (BHL 8771); datation: 1306/1322.

Ed. AASS, Febr. t. 3, p. 559A-B [3 ed., p. 564A] (c. 4.19).

*Walfardus Augustanus ( $† 1127)$.

Vie anonyme (BHL 8789); datation: peu après 1127.

Ed. AASS, Apr. t. 3, p. 829A [3 ed., p. 838B] (c. 3).

*Walterius ab. Stirpensis (vers 990-1070).

Marbode de Rennes, Vie (BHL 8802); datation: avant 1096 ?

Ed. AASS, Maii t. 2, p. 703A-B [3 ${ }^{\mathrm{e}}$ ed., p. 700F-701B] (c. 1.5)

*Wido ab. Pomposianus ( $\uparrow$ 1046).

Vie anonyme ( $B H L$ 8876); datation: peu après 1046.

Ed. $A A S S$, Mart. t. 3, p. 914B-C [3ed., p. 909B-C] (c. 2.10).

*Willelmus Firmatus ( $†$ vers 1100 ).

Étienne de Fougères, Vie (BHL 8914); datation: avant 1179.

Ed. AASS, Apr. t. 3, p. 335A [3 ${ }^{\mathrm{e}}$ ed., p. 337B] (c. 1.2).

*Willelmus Magnus ( $\dagger 1157)$.

Théobald, Vie ( $B H L$ 8923); datation: fin XIII ${ }^{\mathrm{e}} \mathrm{s}$.

Ed. $A A S S$, Febr. t. 2, p. $455 \mathrm{C}-\mathrm{D}\left[3^{\mathrm{e}}\right.$ ed., p. $\left.456 \mathrm{~B}-\mathrm{C}\right]$ (c. 3.16$)$.

*Willelmus ab. S. Benigni (962-1031).

Vie anonyme (non recensée dans la $B H L$ ); datation: peu après 1031.

Ed. E. BOUgaud - J. GARNIER, Chronique de l'abbaye Saint-Bénigne de Dijon,

Dijon, 1875, p. 131. 